\title{
Microstructure and Texture Evolution during Friction Stir Processing of Fully Lamellar Ti-6Al-4V
}

\begin{abstract}
A.L. PILCHAK and J.C. WILLIAMS
Friction stir processing (FSP) was used to locally refine a thin surface layer of the coarse, fully lamellar microstructure of investment-cast Ti-6Al-4V. Depending on the peak temperature reached in the stir zone during processing relative to the $\beta$ transus, three distinct classes of microstructures were observed. Using accepted wrought product terminology, they are equiaxed, bimodal, and lamellar, except for the case of FSP, the length scale of each was smaller by at least an order of magnitude compared to typical wrought material. The evolution of an initially strain-free fully lamellar microstructure to each of these three refined conditions was characterized with scanning electron microscopy, transmission electron microscopy and electron backscatter diffraction. The fundamental mechanisms underlying grain refinement during FSP, including both the morphological changes and the formation of high-angle grain boundaries, were discussed.
\end{abstract}

DOI: $10.1007 / \mathrm{s} 11661-010-0434-9$

(c) The Minerals, Metals \& Materials Society and ASM International 2010

\section{INTRODUCTION}

FRICTION stir processing (FSP) is a solid-state metal working technique based on the principles of friction stir welding (FSW). FSP and FSW involve plunging a rotating, cylindrical tool that has an extended, concentric pin with a smaller diameter into a plate, or a seam between two plates, and traversing the tool across it. Friction between the tool and workpiece generates extreme temperatures, which lower the flow stress of the material and permit significant amounts of plasticity in the vicinity of the rotating tool. This, in turn, imparts substantial strain to the workpiece resulting in refinement of the microstructure. During FSP, no weld is created so the tool plunge depth becomes a process parameter that can be used to adjust the total heat input into workpiece in order to tailor the stir zone microstructure.

There has been recent interest in FSP of cast alloys, ${ }^{[1]}$ which have intrinsically lower strength and ductility due to the coarse grains prevalent throughout the as-cast microstructure. In fact, the process has been used to refine the microstructure of cast aluminum, ${ }^{[2,3]}$ magnesium $^{[1]}$ and nickel-aluminum-bronze alloys. ${ }^{[4-6]}$ Recent work by the present authors showed that FSP can also be used to refine the coarse, fully lamellar microstructure of investment-cast and hot isostatic pressed Ti-6Al-4V

A.L. PILCHAK, formerly Graduate Research Associate, Department of Materials Science and Engineering, The Ohio State University, is Visiting Scientist, Air Force Research Laboratory, Materials and Manufacturing Directorate/RXLM, Wright Patterson Air Force Base, $\mathrm{OH} 45433$, and Research Scientist, University Technology Corporation, Dayton, $\mathrm{OH}$ 45432. Contact e-mail: adam.pilchak@wpafb.af.mil J.C. WILliAMS, Professor and Honda Chair Emeritus, is with the Department of Materials Science and Engineering, The Ohio State University, Columbus, $\mathrm{OH} 43210$.

Manuscript submitted September 27, 2009.

Article published online November 19, 2010
(Ti-6-4). ${ }^{[1,7,8]}$ Different microstructures can be created depending on the peak temperature in the stir zone relative to the $\beta$ transus temperature. During subtransus processing, the stir zone microstructure consisted of approximately $1-\mu \mathrm{m}$ equiaxed $\alpha$ grains, while it consisted of 25- to 30- $\mu \mathrm{m}$ prior $\beta$ grains containing $\alpha+\beta$ colonies during supertransus processing. These were called the $\alpha / \beta$ and $\beta$ friction stir processed conditions, ${ }^{[9,10]}$ respectively, which signified the phases that were present in the stir zone at the peak processing temperature. Both stir zone microstructures were considerably refined from the cast condition, which had prior $\beta$ grains larger than $1 \mathrm{~mm}$ in diameter with colony sizes typically exceeding $500 \mu \mathrm{m}$. The characteristics of the grain refinement mechanism during subtransus FSP were suggested to be consistent with continuous recrystallization ${ }^{[1]}$ as opposed to classical recrystallization via nucleation and growth or dynamic recrystallization. However, additional analyses performed since the preliminary results were published have provided further insight into microstructure evolution during FSP including both the grain refinement mechanism and the resultant texture in the stir zone during both subtransus and supertransus FSP. Since different recrystallization mechanisms fundamentally produce the same final microstructure, i.e., a fine grained structure separated by high-angle boundaries, the present study focuses extensively on the transition zone to identify the operative grain refinement mechanisms. The transition zone is the region between the unaffected base material and the stir zone, which contains deformed, but unrecrystallized, constituents that were present in the base material microstructure. ${ }^{[7]}$ The microstructure gradient in the transition zone provides insight into how the initially strain-free, fully lamellar microstructure was converted to fine, equiaxed $\alpha$ grains. The present investigation addresses the fundamental principles underlying grain refinement and the formation of high-angle grain boundaries in the $\alpha$ phase during FSP. Grain refinement 
during processing in the $\beta$-phase field is also briefly addressed. Due to the similarity of material flow during FSP and FSW of titanium alloys, the results presented here for FSP may also be used to interpret grain refinement during FSW of titanium alloys. Thus, it is useful to review the literature regarding grain refinement during FSP and FSW of $\alpha+\beta$ titanium alloys.

\section{A. Review of Grain Refinement during FSW and Processing of $\alpha+\beta$ Titanium}

Since near- $\alpha$ and $\alpha+\beta$ titanium alloys contain two ductile phases, which deform independently of one another, it is necessary to make the distinction between recrystallization which occurs in the $\beta$ phase from that which occurs in the $\alpha$ phase. This leads to a natural separation of friction stir processes occurring above and below the $\beta$ transus. The latter case is more frequently observed during FSW, especially in thicker sections, where a larger volume of material is stirred and hence higher torques are required than in FSP, which leads to higher peak temperatures. Irrespective of starting material microstructure, ${ }^{[1]}$ the stir zone microstructure resulting from processing or welding above the $\beta$ transus generally consists of fine, equiaxed prior $\beta$ grains decorated by grain boundary $\alpha$ with lamellar $\alpha+\beta$ colonies inside. Grain growth is rapid in the $\beta$-phase field because of the high temperature and the absence of second-phase particles to impede grain boundary motion. Consequently, the prior $\beta$ grain size depends on the time spent above the $\beta$ transus, which is controlled by processing parameters with tool rotation rate having the strongest influence. ${ }^{[12,13]}$ The formation of such a microstructure has been described by several researchers. For instance, early work by Ramirez and Juhas $^{[11]}$ suggested that either dynamic recrystallization or severe deformation restricted grain growth occurs in the $\beta$ phase in the stir zone during welding above the $\beta$ transus. Then, after the tool has passed, there is subsequent nucleation of $\alpha$ phase first at prior $\beta$ grain boundaries followed by growth of $\alpha$ platelets and colonies into the $\beta$ grains. Zhang et al. ${ }^{[13]}$ also suggested that dynamic recrystallization occurs in the $\beta$ phase during FSW above the $\beta$ transus. The basis for the dynamic recrystallization hypothesis was the fact that the prior $\beta$ grain size in the stir zone was finer than in the starting material. Later, however, Zhang et al. ${ }^{[13]}$ also speculated that nucleation of "tiny $\beta$ grains" could also occur after stirring, which is contradictory to the proposition of dynamic recrystallization.

In contrast to both of these studies, Mironov et al. ${ }^{[14]}$ invoked two different recrystallization mechanisms to explain two different types of $\beta$ grain morphology during FSW of Ti-6-4 above the $\beta$ transus. The first was discontinuous recrystallization stimulated by local grain boundary migration, which formed fine scale $\beta$ grains in the stir zone. It is interesting to note that the term "dynamic" was not used, which, as discussed in more detail subsequently, implied that this event did not occur during deformation but rather after the tool had passed. It was stated, however, that the volume fraction of fine $\beta$ grains in the stir zone was small and thus the contribution of the discontinuous recrystallization mechanism was small. The majority of the stir zone was characterized by highly elongated prior $\beta$ grains. While not named explicitly, the recrystallization mechanism was described as preliminary elongation followed by transverse subdivision of the $\beta$ grains. This implies that there was not nucleation of new $\beta$ grains during (or after) deformation but rather a restructuring of the existing $\beta$ grains. The microstructure of the base material was not reported, however, so it is difficult to relate this observation to the initial $\beta$ grain structure. This point is addressed in more detail in Section III-A.

It is typically observed that a region of $\sim 1-\mu \mathrm{m}$ equiaxed $\alpha$ grains is present around the edge of the stir zone, within the transition zone, and occasionally in the stir zone. The presence of equiaxed $\alpha$ grains in these regions is evidence that the periphery of the stir zone did not exceed the $\beta$ transus. As illustrated later, these equiaxed grains are also prevalent throughout the stir zone of material processed or welded below the $\beta$ transus with their volume fraction depending on the peak temperature reached in the stir zone. Thus, it is useful to study the mechanisms by which these grains form in order to choose an appropriate set of processing parameters to achieve the desired final structure. Ramirez and Juhas ${ }^{[1]}$ have reported that since this region does not exceed the $\beta$ transus, the mechanism by which these grains form depends on the state of the starting material microstructure. When the base material was in the fully lamellar condition, Ramirez and $\mathrm{Juhas}^{[11]}$ noted that recrystallization occurred by "globularization" of the $\alpha$ lamellae, although they also used the term "dynamic recrystallization" to describe the same process. In contrast, when the starting structure was in the mill-annealed condition $(\alpha+\beta$ worked and given a moderate stress relief anneal), these grains were reported to form by dynamic recrystallization, which was rationalized on the basis that there was no stored energy in the base material to drive recrystallization so the process must be attributed entirely to the stirring imposed by the tool. Zhang et al. ${ }^{[13]}$ have attempted to describe the formation of equiaxed grains within the heat-affected zone of a Ti-6-4 friction stir weld. The authors claimed that the $\alpha$ lamellae were converted to equiaxed grains in the heat-affected zone to reduce interfacial energy. In fact, the $\alpha / \beta$ interface in a lamellar microstructure has significantly lower energy due to the crystallographic relationships imposed by the Burgers orientation relationship, and heat treating such a microstructure would only result in narrowing of the $\alpha$ lamellae as the volume fraction of $\beta$ phase increases under equilibrium conditions. Thus, an interfacial energy argument is also inappropriate for describing the formation of these grains.

These studies illustrate the need to consider the starting material structure carefully when identifying recrystallization mechanisms. ${ }^{[15]}$ For example, titanium alloys in the mill-annealed condition, such as that used in the two studies described previously, can have a substantial residual dislocation substructure. This is because the mill-annealed condition only implies 
working in the $\alpha+\beta$-field followed by a short time, moderate temperature anneal (a stress relief anneal), which is insufficient to fully recrystallize the microstructure. ${ }^{[16]}$ Thus, any additional thermal cycles will further the evolution of the microstructure when the temperature is sufficiently high for dislocation motion and diffusion thereby permitting substantial changes to the microstructure in these regions without any additional strain imposed by the friction stir tool. Thus, it is considerably more difficult to identify the transition zone and heat-affected zones when the starting material is in the mill-annealed condition. ${ }^{[7,10]}$

While the previous discussion has focused primarily on the material within the processed zone that exceeded the $\beta$ transus, there have also been reports of subtransus welding and processing. In this case, both $\alpha$ and $\beta$ phases are present in the stir zone during welding or processing. For instance, Zhou et al. ${ }^{[17]}$ analyzed the microstructure in a friction stir weld made in 2-mm-thick Ti-6-4 sheet and observed a bimodal microstructure consisting of fine equiaxed $\alpha$ and lamellar $\alpha+\beta$. The authors reported that the fine equiaxed $\alpha$ grains were formed by dynamic recrystallization. However, the evidence provided for the dynamic recrystallization mechanism was that the equiaxed $\alpha$ was "dislocation free" and that there were high-angle boundaries present between the $\alpha$ grains in the stir zone. The former observation was based on transmission electron microscopy (TEM) analysis, while the latter was interpreted from electron backscatter diffraction data. While a mean primary $\alpha$ grain size of $\sim 5 \mu \mathrm{m}$ is reported, the equiaxed $\alpha$ grains appeared to be less than $1 \mu \mathrm{m}$ in diameter in the TEM images with very fine $\alpha$ laths, on the order of $200 \mathrm{~nm}$, in the lamellar constituent of the bimodal microstructure. The EBSD analysis was performed with a step size of $0.5 \mu \mathrm{m}$, and therefore, it was not possible to capture the fine details regarding the distribution of local grain misorientations. In particular, it is not possible to determine the relative contributions of the equiaxed $\alpha / \alpha$ colony boundaries and equiaxed $\alpha /$ equiaxed $\alpha$ boundaries to the misorientation-angle distribution. Thus, these two features alone are insufficient evidence of dynamic recrystallization as the same characteristics would be observed if any number of other recrystallization mechanisms were operative. Zhou et al. ${ }^{[17]}$ go on to suggest that "continuous dynamic recrystallization" might be active, which the authors define as "continuous formation of transverse grain boundaries across the $\alpha$ phase and subsequent diffusion penetration of the $\beta$ phase along these boundaries." The authors cited an article on static globularization of Ti-6-4 (also called spherodization, this terminology is explained in more detail subsequently); however, the article ${ }^{[18]}$ suggested that the kinetics of static globularization were rather sluggish requiring times of hours to complete at temperatures as high as $900{ }^{\circ} \mathrm{C}$ and $955^{\circ} \mathrm{C}$. The times at temperature during FSW and processing are much shorter and can be typically expressed in seconds. ${ }^{[19]}$ Thus, the contribution of long-range diffusional processes to spherodization during FSW and FSP is negligible, especially for thin sheet material such as that studied by Zhou et al. ${ }^{[17]}$ Juhas et al. ${ }^{[20]}$ have also observed a similar microstructure as that reported by Zhou et al. ${ }^{[17]}$ and suggested that these grains form either by dynamic recrystallization or by nucleation and growth. The latter seems unlikely since nucleation and growth of $\alpha$ phase results in the formation of lamellar microstructures, which were also observed in the stir zone.

Our previous investigation ${ }^{[1]}$ showed that a significant $\alpha$-phase lattice rotation accompanied the transformation from coarse lamellar to fine equiaxed morphology during FSP of investment-cast Ti-6Al-4V. The lattice rotation was manifested as networks of low-angle boundaries within $\alpha$ lamellae that were developed in the transition zone and gradually increased in misorientation near the stir zone. Given that the base material was cast, hot isostatically pressed (HIP'ed) and annealed followed by slow cooling, there was no dislocation substructure present in the starting condition that could have contributed to formation of these boundaries. Thus, the formation of such a cellular network of lowangle boundaries, which transformed to high-angle boundaries, was due to FSP. However, due to the constraint imposed by the $\beta$ phase on either side of the $\alpha$ lamellae and the relatively short time at temperature during FSP, there was not uniform coarsening of the subgrain structure as would be expected in a true continuous recrystallization process. Thus, one of the purposes of the present investigation is to clarify and further elaborate on the continuous recrystallization mechanism proposed in the earlier article. ${ }^{[1]}$

\section{B. Review of Recrystallization Terminology}

Based on this brief review, it is evident that there is a general lack of consensus regarding recrystallization processes during FSW and FSP of titanium alloys. In addition, recrystallization terminology can often be a source of confusion, and so the following paragraphs are meant to provide a concise summary of the definitions of the terms frequently used in the FSW and FSP literature as they are widely accepted in metallurgy and materials science. The reader is referred to the articles by Doherty et al. ${ }^{[21]}$ and Humphreys ${ }^{[22]}$ for a more thorough treatment of recrystallization mechanisms and terminology. For recrystallization behavior of $\alpha+\beta$ titanium alloys, the reader is referred to the articles by Peters et al. ${ }^{[23]}$ and Semiatin and co-workers. ${ }^{[18,24-28]}$

In the simplest form, conventional (also called "static" or "primary") recrystallization can be defined as the nucleation of new strain-free grains that have high-angle boundaries with respect to the surrounding deformed matrix and subsequent migration of the grain boundaries to consume the material in the deformed state. This is driven by the stored energy due to deformation, which is manifested as high dislocation content in the deformed material. Thus, the nucleation of a new grain results in a net reduction in free energy per unit volume. In general, high-angle boundaries are regarded as those having misorientation greater than $\sim 15$ deg with respect to the surrounding microstructure. While the classical depiction of recrystallization in 
textbooks suggests that new nuclei form on an atomby-atom basis, Cahn ${ }^{[29]}$ proposed that the nuclei are actually regions already present in the deformed microstructure. During deformation, dislocations tend to arrange themselves into structures such as cellular arrays, subgrains, or slip bands, all of which could lead to the formation of a critical nucleus. In titanium alloys, the dislocation arrangement is a function of deformation temperature and alloy composition, especially aluminum $^{[30]}$ and oxygen. ${ }^{[31]}$ From the deformed state, conventional recrystallization can proceed as either a continuous or discontinuous process. The latter is the classical view of recrystallization that is often referred to as "nucleation and growth," which initiates in localized regions in the microstructure and advances as a "recrystallization front" with long-range motion of grain boundaries. In contrast, continuous recrystallization reactions are those in which the microstructure evolves homogeneously throughout. In this case, there is no sharp recrystallization front and subgrains (or grains) coarsen uniformly. In continuous processes, the formation of high-angle boundaries is due to recovery processes, which gradually increase the misorientation of the subgrain (or grain) boundaries during annealing. As defined by Doherty et al., ${ }^{[21]}$ recovery processes occur by dislocation rearrangement and annihilation during annealing but do not result in the movement of a high-angle boundary. However, short-range motion of grain boundaries is observed during continuous recrystallization, which provide the basis for terming this a recrystallization process as opposed to one of extended recovery. $^{[21]}$

Adding the adjective "dynamic" in front of recrystallization implies that the process occurs concurrently with straining. Just as in the case of conventional recrystallization, dynamic recrystallization can also be either a continuous or discontinuous process, which describes how the transformation occurs spatially. In the former (continuous dynamic recrystallization), new grains with high-angle boundaries form homogeneously throughout the microstructure, while in the latter, the transformation is initially localized at certain areas in the microstructure and gradually increases in magnitude. Discontinuous dynamic recrystallization might be expected in plastically anisotropic materials or in materials that exhibit strain localization (often due to adiabatic shear) where there is heterogeneous strain accumulation. It is emphasized that in both cases, there is nucleation and growth of new grains with high-angle boundaries and the continuous/ discontinuous terms only describe the spatial nature of the recrystallization reaction. On the other hand, if refinement of an initially strain-free microstructure concurrent with deformation proceeds first by the generation of a subgrain network followed by an increase in misorientation across the subgrains by repeated absorption of dislocations and finally uniform coarsening of this substructure, the reaction is known as dynamic continuous recrystallization. ${ }^{[15,21]}$ It is worth reiterating that this is a different process than continuous dynamic recrystallization, which was described previously, and in the strictest sense, the two terms should not be used interchangeably. The similarity between the two terms is unfortunate; however, each is an accurate description of the phenomenon that they describe.

Further complicating the issues of recrystallization as they relate to titanium alloys, the conversion from coarse lamellar $\alpha$-phase morphology to equiaxed $\alpha$ has come to be widely known as "spherodization" or globularization in the literature. ${ }^{[18,24-28]}$ These terms are preferred to "recrystallization" to describe this type of grain refinement to emphasize that the process is distinct from conventional recrystallization in that strain-free grains with high-angle boundaries are not formed, but rather there is a change in the $\alpha$-phase morphology. It is not possible to transform a fully lamellar microstructure to an equiaxed one by heat treatment alone, because the lamellar morphology has low energy interfaces as a result of the crystallography imposed by the Burgers orientation relationship. Thus, an intermediate deformation step followed by annealing is necessary to form equiaxed grains. Both dynamic and static recovery processes can contribute to spherodization with the relative contribution of each being dependent on the exact thermomechanical history (temperature, $\varepsilon$, and $\dot{\varepsilon}$ ) experienced by the material. Spherodization and globularization are forms of continuous recrystallization reactions that occur by extended recovery processes. The formation of large microtextured regions during hot working ${ }^{[24,32,33]}$ is direct evidence that conventional and dynamic recrystallization seldom occur in $\alpha+\beta$ titanium alloys. The term microtexture means that many grains that appear recrystallized in the morphological sense, i.e., are equiaxed, actually share a common $c$-axis orientation over a long range in the microstructure. The size of these regions can usually be linked to the $\alpha$ colony size before working. ${ }^{[24,32,33]}$ Static spherodization processes require a deformation step and then rely on recovery and thermally activated dislocation motion to rearrange dislocation substructure during postdeformation annealing. Stefansson et al. ${ }^{[26]}$ showed that static spherodization is actually a two-part process. First, segmentation of $\alpha$ lamellae by boundary splitting occurs (separation of $\alpha / \alpha$ boundaries by penetration of the $\beta$ phase ${ }^{[23,34]}$ ) followed by classical coarsening mechanisms such as Ostwald ripening and termination migration. ${ }^{[26]}$ As mentioned previously, the kinetics of the static spherodization process are relatively sluggish in two-phase titanium alloys where there are large composition differences between the phases. This is primarily due to the partitioning of vanadium to the $\beta$ phase and the large diffusion distances required for $\beta$-phase boundary migration. Spherodization can occur concurrently with straining, which would be termed dynamic spherodization (or dynamic globularization). In this case, the applied stress can also influence dislocation motion in addition to the thermally activated component. While these terms are phenomenologically accurate, it is still useful to identify the physical mechanism by which the change in morphology occurs during FSP and FSW, which is a central theme of the current research. 


\section{MATERIALS AND EXPERIMENTAL METHODS}

\section{A. Base Material}

The base material used in this study was investmentcast and HIP'ed Ti-6Al-4V. Plates with approximate dimensions of $175 \times 175 \times 1.5 \mathrm{~cm}$ were provided by Precision Castparts Corp. (Portland, OR) in the gritblasted and chemically milled condition. The as-cast plates were hipped at a pressure of $101.3 \mathrm{MPa}$ at $1169 \mathrm{~K}$ $\left(896^{\circ} \mathrm{C}\right.$ ) for 2 hours followed by slow cooling in order to heal internal residual casting porosity. An additional 2-hour anneal at $1118 \mathrm{~K}\left(845^{\circ} \mathrm{C}\right)$ followed by slow cooling ensured that the starting material was free from residual stresses. The iron and oxygen contents of the cast plates were 0.23 and 0.19 wt pct, respectively. The resultant microstructure consisted of prior $\beta$ grains in the range of 0.5 to $2 \mathrm{~mm}$, which contained a coarse, fully lamellar $\alpha+\beta$ colony structure. The $\alpha$ colony size was as large as 500 to $700 \mu \mathrm{m}$ in some locations in the microstructure, usually when the colony was connected to grain boundary $\alpha$. The base material microstructure is shown at two levels of magnification in Figure 1.

\section{B. Friction Stir Processing}

Two cast and HIP'ed plates were friction stir processed at the University of South Carolina (Columbia, SC), while one additional plate was processed at the Edison Welding Institute (Columbus, $\mathrm{OH}$ ). The surfaces of the plates were made flat and parallel by milling in order to facilitate FSP. A total of five different sets of processing parameters were investigated, which are outlined in Table I. The letter A or B preceding each set of process parameters indicates the tool that was used for processing. Both tools were smooth and featureless; i.e., they contained no flutes or threads. Tool A had a shoulder diameter of $19.05 \mathrm{~mm}$ with a 5.08 -mm-diameter extended pin that had a length of $1.27 \mathrm{~mm}$. A 1 deg back tilt was used for all processing with this tool. Tool B had a larger diameter pin that was tapered at approximately $30 \mathrm{deg}$ relative to the shoulder. Both the shoulder and pin were larger than that of tool A. Additional details of the processing have been described elsewhere. ${ }^{[7,8,12]}$

\section{Electron Microscopy}

Specimens for metallographic examination were sectioned from the as friction stir processed plate using an electrical discharge machine (EDM). The samples were then ground and polished using successively finer $\mathrm{SiC}$ papers. Final polishing was performed using $0.05-\mu \mathrm{m}$ noncrystallizing colloidal silica in a vibratory polisher. The specimens were examined in an FEI Sirion (FEI Company, Hillsboro, OR) scanning electron microscope (SEM), which had a field emission source. The SEM was
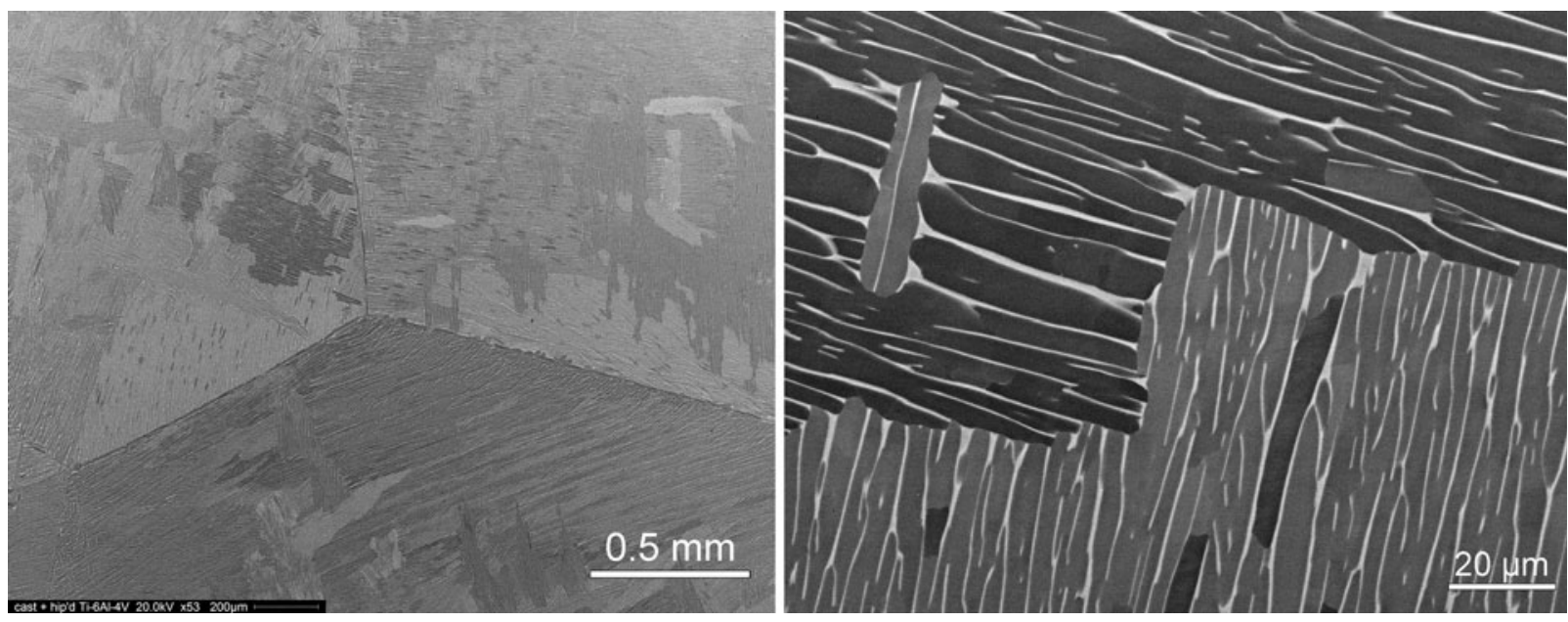

Fig. 1-Backscattered electron micrograph of the investment-cast base material. No evidence of secondary $\alpha$ precipitation within the $\beta$ phase was detected.

Table I. Processing Parameters and Sample Identification Used throughout This Study

\begin{tabular}{|c|c|c|c|c|c|}
\hline $\begin{array}{l}\text { Process } \\
\text { Parameters }\end{array}$ & $\begin{array}{l}\text { Tool Travel, } \mathrm{cm} / \mathrm{min} \\
\text { (in. } / \mathrm{min} \text { ) }\end{array}$ & $\begin{array}{l}\text { Tool Rotation } \\
\text { Speed (rpm) }\end{array}$ & $\begin{array}{l}\text { Down Force, } \\
\text { kN (lbf) }\end{array}$ & $\begin{array}{c}\text { Plunge Depth, } \\
\text { mm (in.) }\end{array}$ & Condition \\
\hline A2-100 & $5.1(2)$ & 100 & $16.5(3700)$ & $\sim 1.8(0.07)^{*}$ & $\alpha / \beta$ \\
\hline A4-100 & $10.2(4)$ & 100 & $38.7(8700)$ & $\sim 1.8(0.07)^{*}$ & $\alpha / \beta$ \\
\hline A4- 150 & $10.2(4)$ & 150 & $14.7(3300)$ & $\sim 1.8(0.07)^{*}$ & high $\alpha / \beta$ \\
\hline B2-150 & 5.1 (2) & 150 & $15.2(3418)^{* *}$ & $2.54(0.10)$ & $\beta$ \\
\hline B4-150 & $10.2(4)$ & 150 & $19.6(4405)^{* *}$ & $2.54(0.10)$ & $\beta$ \\
\hline
\end{tabular}

*Plunge depth was estimated from metallographic sections, because the plates were processed in load control.

**Down force is averaged over the steady-state processing regime (not including the spike in load during plunging or reduction in load during retraction), because depth control was used for these passes. 
operated at an accelerating voltage of $20 \mathrm{kV}$ and an electron "spot size" of 5.0 with the specimens at a working distance of $5.0 \mathrm{~mm}$.

Thin foils for TEM analysis were prepared by first sectioning blanks from the friction stir processed plate using a slow speed diamond saw. Then, the blanks were mechanically polished with successively finer $\mathrm{SiC}$ paper using a precision parallel polisher. The samples were polished through a 1200 grit $\mathrm{SiC}$ surface finish on both sides, ending when the specimen reached a thickness of $120 \mu \mathrm{m}$. Discs $3 \mathrm{~mm}$ in diameter were extracted from the thinned wafer using a rotating steel trepanning tool and abrasive slurry. The foils were thinned until perforation with a jet polisher using a solution of $600 \mathrm{~mL}$ methanol, $360 \mathrm{~mL}$, and $60 \mathrm{~mL}$ perchloric acid at $-45^{\circ} \mathrm{C}$ at $-22 \mathrm{~V}$. The thin foils exhibited the "interface phase,",[35] which is typical of electrothinned foils of two-phase titanium alloys; however, this did not mask the features of interest in the present study, which were constituent morphology and dislocation arrangements. The foils were examined in both bright-field and dark-field mode via scanning transmission electron microscopy (STEM) using a FEI Tecnai TF20 (FEI Company) operating at $200 \mathrm{kV}$.

EBSD data was acquired in an XL-30 ESEM (FEI Company), which had a field emission source. The SEM was operated in high vacuum mode at $20 \mathrm{kV}$ with a beam current of approximately $2.5 \mathrm{nA}$. The specimens were positioned at a working distance of $21.0 \mathrm{~mm}$ and inclined such that the incident electron beam made an angle of $20 \mathrm{deg}$ with the polished surface of the sample. Beam control scans were acquired with step sizes between 0.35 and $1.0 \mu \mathrm{m}$ depending on the length scale of the features of interest in the area under investigation.

\section{Automated reconstruction of prior $\beta$ grain orientations}

Since FSP occurs at elevated temperature, it is of interest to know the crystallographic texture at the deformation temperature. However, because of the $\beta \rightarrow \alpha$ allotropic phase transformation, the texture of the high-temperature phase is masked by the high volume fraction of transformation product in Ti-6-4. The crystallographic relationship between the parent and product phases formed during the $\beta \rightarrow \alpha$ structural phase transformation was first reported by Burgers ${ }^{[36]}$ as being $(0001)_{\alpha} \|\{110\}_{\beta}$ and $\langle 11 \overline{2} 0\rangle_{\alpha} \|\langle 111\rangle_{\beta}$. Due to crystal symmetries of the parent and product phases, there are only 12 possible $\alpha$-phase orientations that can be inherited from a given prior $\beta$ grain. The inverse problem, that is, determining the parent $\beta$ grain orientation from a group of inherited $\alpha$ variants has received considerable attention. ${ }^{[37-39]}$ In general, it is possible to calculate the unique $\beta$ orientation with knowledge of the orientation of three $\alpha$ variants, ${ }^{[37,38]}$ although four are required under certain circumstances, as discussed by Cayron. ${ }^{\text {[39] }}$

In the present approach, reconstruction of the $\beta$ orientations was performed using of the equations presented by Glavicic et al. $;^{[37,38]}$ however, the quaternion parameterization of orientation space was used as opposed to rotation matrices. Additionally, colonies and their first nearest neighbors were considered for the calculation opposed to employing the Monte Carlo method, which permitted handling of large data sets by reducing the total number of calculations. A quaternion completely describes a crystallographic orientation with a single four-index vector. Each quaternion, $Q$, has two parts: a scalar $\mathbf{q}_{0}$ that is $\geq 0$, which contains information about the angle of rotation about the unit vector $\left(\mathbf{q}_{1}, \mathbf{q}_{2}\right.$, $\mathbf{q}_{3}$ ). Collectively, these two parts represent a point on the upper half of a unit sphere. ${ }^{[40]}$ Each $Q=\left(\mathbf{q}_{0}, \mathbf{q}_{1}, \mathbf{q}_{2}, \mathbf{q}_{3}\right)$ is normalized by the relationship $|Q|=\left[\mathbf{q}_{0}^{2}+\mathbf{q}_{1}^{2}+\mathbf{q}_{2}^{2}+\right.$ $\left.\mathbf{q}_{0}^{2}\right]^{1 / 2}$. The scalar is related to the rotation angle, $\omega$, by $\mathbf{q}_{0}=\cos (\omega / 2)$, while the rotation axis, $n$, can be extracted with the relationship $\mathbf{q}=n \sin (\omega / 2)$. The quaternion parameterization was used in order to implement an array-based approach in MATLAB (The Mathworks, Inc., Natick, MA) that was computationally efficient in that it minimized the use of "for" loops. Typical computation times for data sets containing 750,000 data points and several thousand grains were on the order of 8 to 10 minutes using a standard configuration desktop computer with a $2.4 \mathrm{GHz}$ processor and $2 \mathrm{~GB}$ of RAM.

\section{RESULTS AND DISCUSSION}

\section{A. Stir Zone Microstructures}

Despite using five sets of processing parameters, only three distinct stir zone microstructures were observed. The $\alpha / \beta$ (Figure 2(a)) and $\beta$ (Figure 3) friction stir processed conditions ${ }^{[8-10]}$ contained $\sim 1-\mu$ m equiaxed $\alpha$ grains and $\sim 25-\mu \mathrm{m}$ prior $\beta$ grains with lamellar $\alpha+\beta$ colonies, respectively. The third type of microstructure (Figure 2(b)) consisted of $\sim 1-\mu \mathrm{m}$ globular $\alpha$ and fine, acicular $\alpha+\beta$. This type of microstructure is subsequently referred to as the "high $\alpha / \beta$ condition," indicating that it was at a higher temperature in the $\alpha+$ $\beta$-phase field than the $\alpha / \beta$ condition and, as a result, had a smaller volume fraction of globular $\alpha$. This was similar to bimodal microstructures observed in $\alpha+\beta$ titanium alloys forged at an elevated temperature in the $\alpha+$ $\beta$-phase field followed by air cooling; however, the length scale of each constituent was approximately an order of magnitude smaller than those observed in conventional forgings. The volume fraction of globular $\alpha$ varied widely, indicating that there were temperature gradients present throughout the stir zone. The volume fraction of globular $\alpha$ was generally smallest in the central stir zone, typically 15 pct or less, which gradually increased to 30 to 50 pct at the periphery of the stir zone. The rest of the microstructure consisted of fine $\alpha+\beta$ colonies and an interpenetrating mixture of $\alpha$ lamellae. The lamellar regions of the microstructure were $\beta$ phase at the processing temperature and subsequently transformed to $\alpha$ by nucleation and growth after the tool had passed, which formed the bimodal microstructure.

STEM analysis of the stir zone of the subtransus processed conditions provided additional insight into the state of the microstructure. The majority of the stir zone in the $\alpha / \beta$ friction stir processed condition 


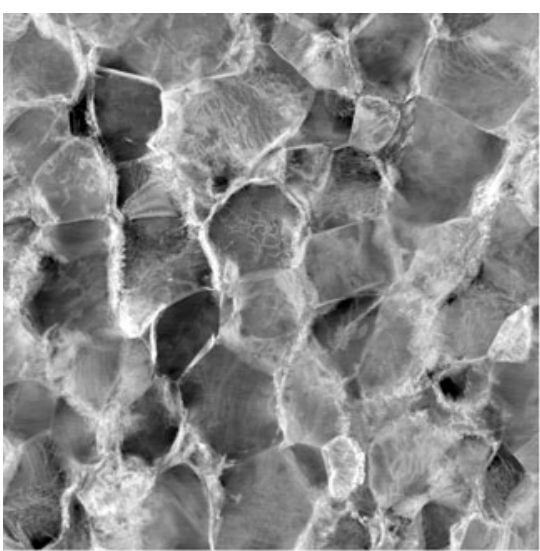

$1 \mu \mathrm{m}$ (a)

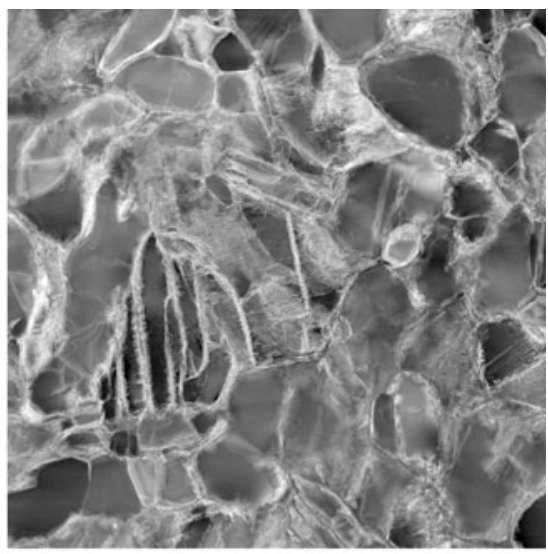

$1 \mu \mathrm{m}$ (b)

Fig. 2-STEM images of the stir zone microstructure in $(a)$ the $\alpha / \beta$ and $(b)$ the high $\alpha / \beta$ friction stir processed conditions.

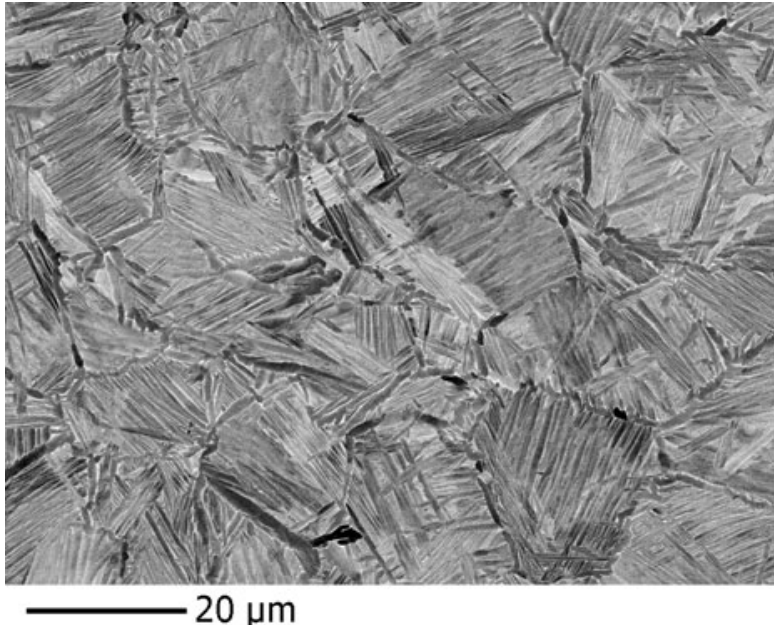

Fig. 3-Stir zone microstructure in the $\beta$ friction stir processed condition (processing parameters B4-150).

consisted of equiaxed $\alpha$ grains separated by high-angle $\alpha / \alpha$ grain boundaries. Dislocations were present inside the majority of these grains that were either tangled (Figures 4(a) and (b)) or organized into low energy arrays like hexagonal networks (Figure 4(c)). The latter arrangement was consistent with the occurrence of hightemperature recovery in the present alloy. ${ }^{[41]} \mathrm{It}$ is noted, however, that despite the large strains and high strain rates during FSP, a relatively low dislocation density remained in the final microstructure of the $\alpha / \beta$ condition. It is likely that the short length scale in the stir zone microstructures provided many opportunities for dislocation annihilation at grain boundaries.

As a comparison, the equiaxed $\alpha$ grains in the high $\alpha / \beta$ condition had even lower dislocation density (Figures 2(b) and 4(d)). A possible source for this difference was related to the relative amounts of $\alpha$ and $\beta$ phase present at the processing temperature. In the high $\alpha / \beta$ condition, a significant fraction (between 50 and $85 \mathrm{pct}$ ) of the microstructure would have been $\beta$ phase, which has much lower flow stress at elevated temperature, so it is possible that strain was preferentially partitioned to the $\beta$ phase during FSP. The $\alpha$ lamellae within the transformed $\beta$ regions were also observed to be generally free from dislocations. This observation is important because it implies that the tool had passed and there was no further deformation applied during or after the allotropic transformation.

The presence of equiaxed $\alpha$ grains in the stir zone implied that the peak temperature during FSP remained below the $\beta$ transus. On the other hand, when processed above the $\beta$ transus, the stir zone microstructure consisted of fine prior $\beta$ grains containing lamellar $\alpha+\beta$ colonies (Figure 3). This microstructure was consistent with those formed by cooling from the $\beta$-phase field; however, there are a few notable differences. First and foremost, the prior $\beta$ grain size was small, on the order of $25 \mu \mathrm{m}$. Second, the grain boundary $\alpha$ that delineates the prior $\beta$ grain boundaries was considerably thicker than any of the $\alpha$ lamellae within the grains. Initially, it was believed that the diffusion of oxygen into the workpiece and segregation of $\mathrm{O}$ to the grain boundaries during processing resulted in the formation of thick grain boundary $\alpha$ during cooling. However, chemical analysis by inert gas fusion methods (ASTM E 1409-08) showed there was no additional oxygen within the stir zone on the bulk scale compared to that in the base material. Finally, despite their small size, there were many $\alpha$ variants visible within each $\beta$ grain, resulting in a very fine microstructural length scale.

The prior $\beta$ grain morphology depended on the position and direction of observation. For example, the grains were nominally equiaxed in the central stir zone, but tended to be elongated in the local shear direction on the advancing and retreating sides. Similar observations were made by Lienert et al. ${ }^{[42]}$ and Mironov et $a l^{[14]}$ for friction stir welded Ti-6-4. Mironov et al. ${ }^{[14]}$ interpret this as evidence that the grain refinement mechanism is "elongation and transverse subdivision" of the $\beta$ grains. These observations were made on the advancing and retreating side transition zones both inside and outside what the authors demarcated as the stir zone border. The network of prior $\beta$ grain boundaries was determined from EBSD data using the method proposed by Gey and Humbert ${ }^{[43]}$ that relied on the 


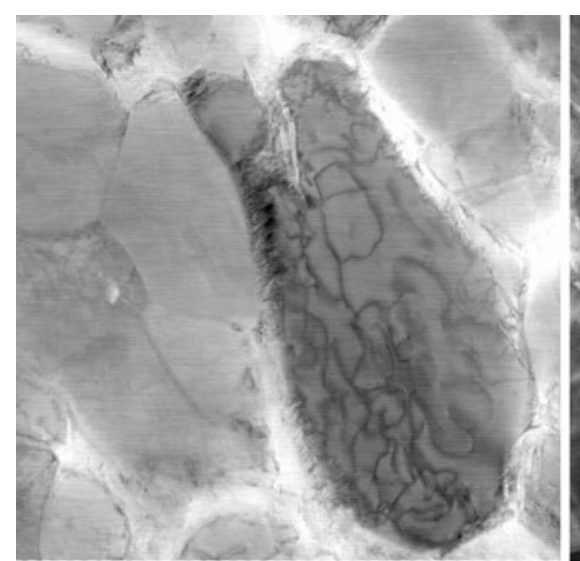

$1 \mu \mathrm{m} \quad(a)$

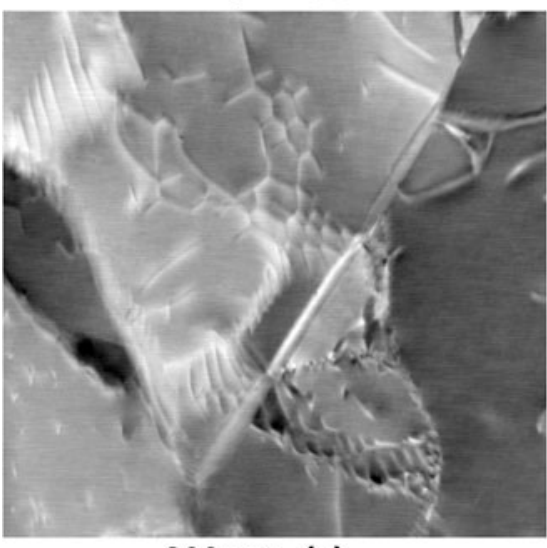

$200 \mathrm{~nm}$ (c)

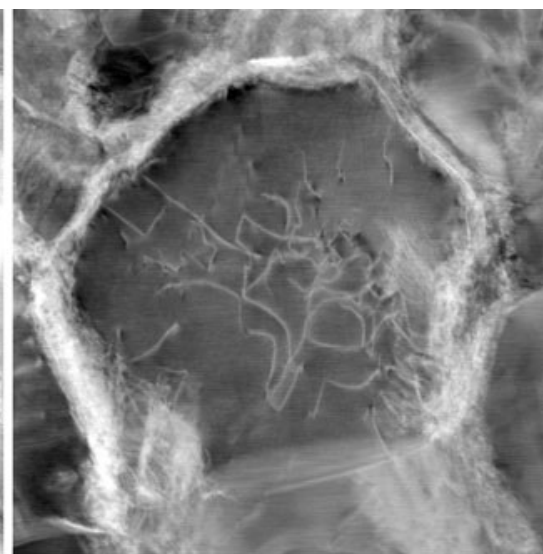

$=250 \mathrm{~nm}$ (b)

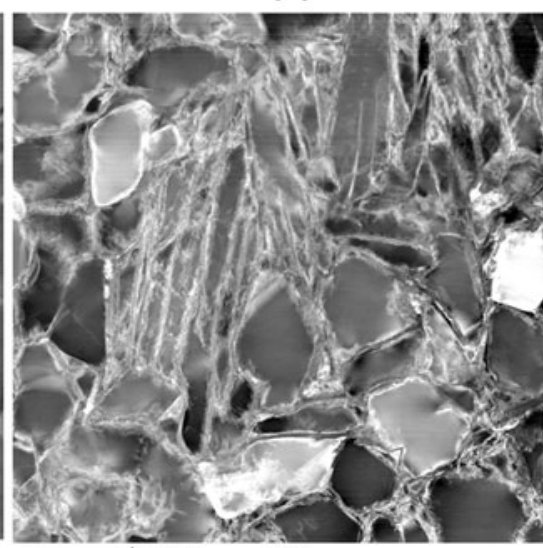

(d)

Fig. 4-STEM images showing a relatively low dislocation content in the $(a)$ through $(c) \alpha / \beta$ friction stir processed condition and even lower content in $(d)$ the high $\alpha / \beta$ friction stir processed condition.

misorientation angle across $\alpha / \alpha$ boundaries. If the misorientation angle is contained within a range of angles for adjacent colonies inherited from the same parent $\beta$ grain, as dictated by the Burgers orientation relationship, the boundary is said to be an $\alpha$ colony boundary. All remaining boundaries, which are not colony boundaries, are believed to be prior $\beta$ grain boundaries. This approach does not determine the actual orientation of the $\beta$ grains and is only applicable if the microstructure is in the fully lamellar condition; i.e., there are no equiaxed constituents present. Based on this procedure, Mironov et al..$^{[14]}$ observed features on the stir zone side of the "stir zone border," which the authors referred to as "bulges" that tended to form fine $\beta$ grains; however, we believe they are an artifact of the reconstruction method and not evidence of a grain refinement mechanism. Mironov et al. ${ }^{[14]}$ reported that there are high aspect ratio $\beta$ grains on the base metal side of the stir zone border, which, in some cases, contain a transverse sub-boundary. Since details of the base material microstructure* were not reported by

\footnotetext{
*Examination of the macroetched image reported in the article suggests the microstructure is in the mill-annealed condition.
}

Mironov et al. ${ }^{[14]}$ it is only possible to speculate on the origin of these features by relating them to two features that were observed repeatedly during FSW and FSP of $\alpha+\beta$ titanium alloys regardless of starting material microstructure. ${ }^{[7,9-12,20,42,44]}$ The first is the presence of equiaxed $\alpha$ phase around the periphery of the stir zone in very close proximity to the stir zone border. These grains were observed when the starting material was in the mill-annealed, ${ }^{[11]}$ fully lamellar, ${ }^{[7,9,11]}$ and bimodal conditions ${ }^{[20]}$ and are indicative of the steep temperature gradient through the transition zone, which, by definition, ${ }^{[7]}$ remains below the $\beta$ transus. Due to the deformation imposed in the transition zone and the lattice rotations that accompany the formation of these equiaxed grains, there is no reason that they must still be crystallographically related to the $\alpha$ phase within the adjacent transformed $\beta$ regions of the microstructure that forms by nucleation and growth after the tool has passed. Therefore, this could improperly give rise to the formation of a fine $\beta$ grain using the reconstruction method employed by Mironov et al. ${ }^{[14]}$ Second, if the stir zone side of the border did not exceed the $\beta$ transus, then the base material side of the stir zone/transition zone border surely could not have since it is further from the heat source. As a result, this region must still contain 
a significant amount of the base material, which did not reach sufficient temperature to go through the $\beta \rightarrow \alpha \rightarrow$ $\beta$ sequence of phase transformations. Therefore, the " $\beta$ grain boundaries" reconstructed in this region (for example, Figures 2(c) and (d) of Reference 14), if the starting material was truly in the mill-annealed condition, are not representative of any new $\beta$ grain formation and rather reflect $\alpha / \alpha$ boundaries that are not expected to maintain any crystallographic relationships among one another. In addition to these concerns, it is also noted that similar bulges can be seen within prior $\beta$ grains in Figures 7(a) and 9(a) of the original article by Gey and Humbert. ${ }^{[4]}$ The former figure shows a specimen with a colony microstructure that received only a thermal cycle and no prior deformation. Considering these possible sources of error, the reported formation of $\beta$ grains during FSW and FSP must remain an open question that warrants additional investigation.

\section{B. Transition Zone Microstructures}

While the stir zone microstructure was relatively homogeneous throughout, the transition zone microstructure varied considerably depending on the location of observation and the orientation of the adjacent colony. ${ }^{[7]}$ Thus, this section illustrates general differences among the transition zones in each condition. An image of the transition zone from a longitudinal section through the stir zone of the $\alpha / \beta$ friction stir processed condition is shown in Figure 5(a). The metallographic section was taken along the center line of the processed zone, which shows the colonies bending in the direction of tool travel while there is a gradual change from lamellar to globular morphology. There was also an abrupt termination of grain boundary $\alpha$ at the stir zone. Contrast gradients consistent with subgrain formation were present in the kinked and deformed $\alpha$ laths. As the lamellae were bent further, the regions of orientation contrast gradually evolved into discrete equiaxed grains that maintained the aligned appearance of a lath structure for several microns before becoming fully equiaxed such that one lath was indistinguishable from the next. In this region of the transition zone, where the long axis of the lamellae become normal to the tool rotation axis and parallel to the tool travel direction, the $\beta$ phase was compressed bringing the $\alpha$ laths nearer to one another. In Figure 5(a), the $\alpha$ laths were physically bent through an angular range of about $75 \mathrm{deg}$ as the tool passed; however, this did not correspond to the amount of lattice rotation. In some instances, localized spherodization occurred within individual laths or colonies in the transition zone. Examples of this are shown in Figure 5(b) and (c), where some lamellae recrystallized about 50 and $75 \mu \mathrm{m}$ deeper in the transition zone than any others in the same general region. Although the precise recrystallization mechanism could not be uniquely identified from the SEM analysis, it was clear that the equiaxed grains were formed by a restructuring of $\alpha$ laths with no evidence that classical discontinuous recrystallization or dynamic

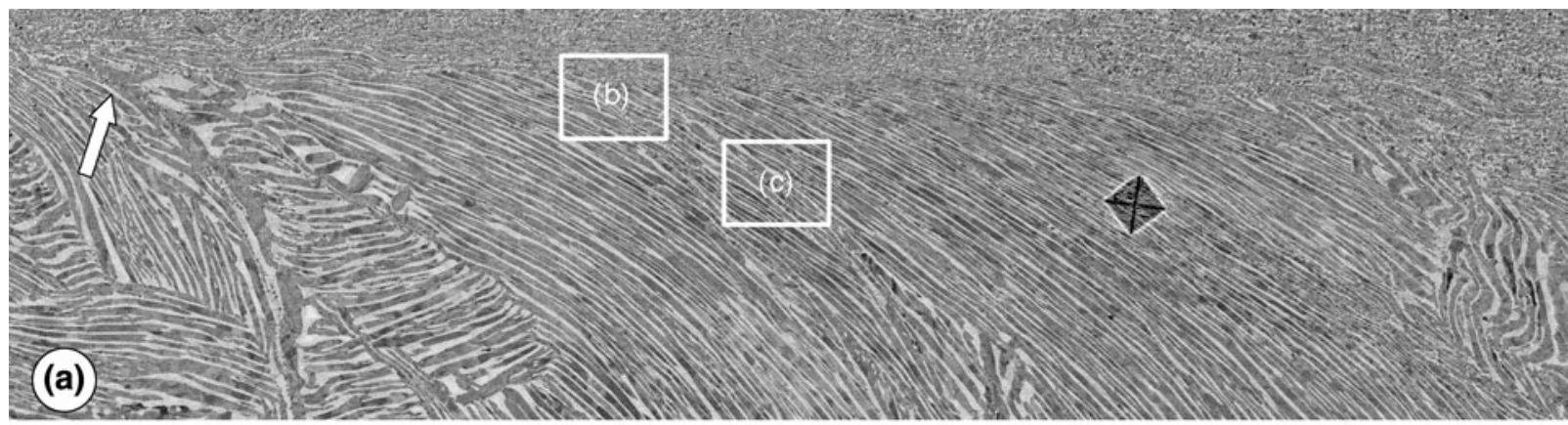

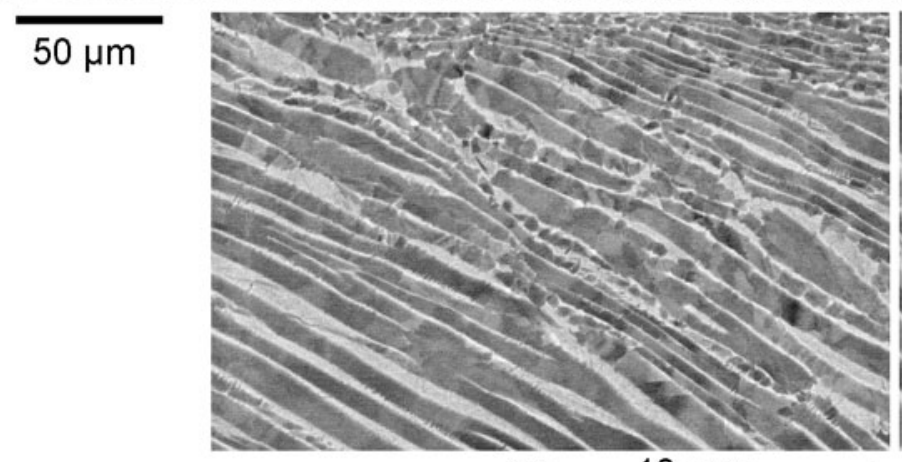

(b)
$10 \mu \mathrm{m}$

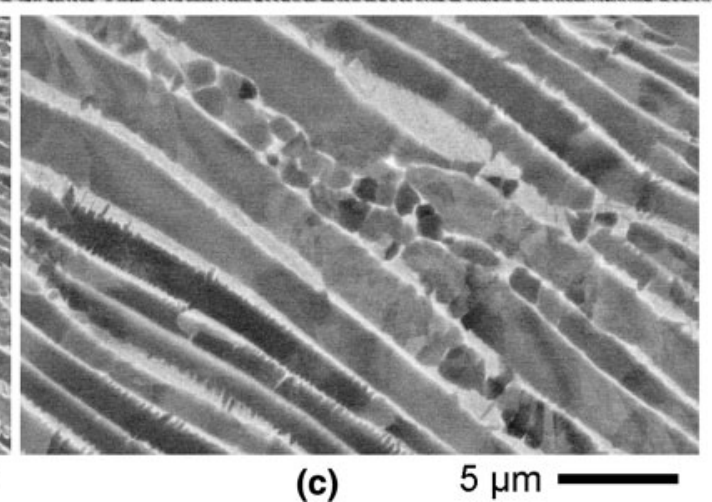

(c)
$5 \mu \mathrm{m}$

Fig. 5-Backscattered electron images of a longitudinal cross section of the $(a)$ transition zone in the $\alpha / \beta$ friction stir processed condition with locations $(b)$ and $(c)$ shown at higher magnification. The tool travel direction is from right to left with the tool rotating clockwise about the vertical direction. The microhardness indent was used to locate this area after tilting for the EBSD experiments described later. The arrow points to grain boundary $\alpha$. 
recrystallization occurred. The transition zone of the high $\alpha / \beta$ condition was similar to the $\alpha / \beta$ friction stir processed condition except that there was a slightly lower volume fraction of primary $\alpha$ lamellae in the former due to the higher peak temperature encountered.

In the $\beta$ friction stir processed condition, the higher peak temperature in the stir zone resulted in a decrease in the volume fraction of $\alpha$ and an increase in the fraction of transformed $\beta$ in the transition zone compared to both of the subtransus processed conditions, as shown in Figure 6. Consistent with the subtransus processed conditions, however, there was extensive subgrain formation within individual $\alpha$ lamellae that gave rise to the formation of $\sim 1-\mu$ m-diameter equiaxed grains (Figure 6(c) and (d)) within the transition zone. After the tool had passed, the regions that were $\beta$ phase at high temperature transformed back to $\alpha$ by nucleation and growth. In the transformed $\beta$ regions within several hundred microns of the stir zone/transition zone border, there was no grain boundary $\alpha$ apparent in the transition zone, suggesting that the $\beta$ phase had not recrystallized yet. This could, however, be a consequence of the large prior $\beta$ grain size in the base material of the present study.

\section{Heat-Affected Zone}

The heat-affected zone was essentially the same for all samples. Since the base material was free of residual strain, the thermal cycle resulted in no significant change in morphology and the $\alpha$ phase remained in the fully lamellar condition. There was, however a gradual increase in the volume fraction $\beta$ phase with decreasing distance from the stir zone. This was indicative of a gradual decrease in the peak temperature at each point successively further from the stir zone. Occasionally within the heat-affected zone, usually at locations deeper in the plate, secondary $\alpha$ precipitation was observed within the $\beta$ lamellae.

\section{EBSD Analysis}

Electron backscatter diffraction was employed for two purposes. The first was to track individual colony orientations in order to study the mechanisms by which the fine equiaxed $\alpha$ grains were formed in the stir zone of the $\alpha / \beta$ and high $\alpha / \beta$ conditions, as well as around the periphery of the stir zone in the $\beta$ friction stir processed condition. Due to the spatially dependent stress state around the friction stir tool, ${ }^{[4]}$ the transition zone was examined at several locations in transverse cross sections, plan view sections and longitudinal sections through the processed plates to obtain a complete understanding of microstructure evolution. Many of these locations had similar characteristics, and thus we report two representative examples: one from the $\alpha / \beta$ condition and one from the $\beta$ friction stir processed condition.

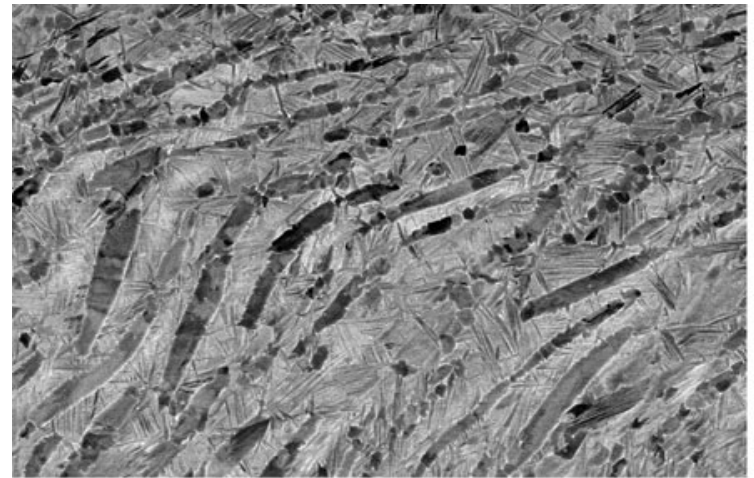

(a)

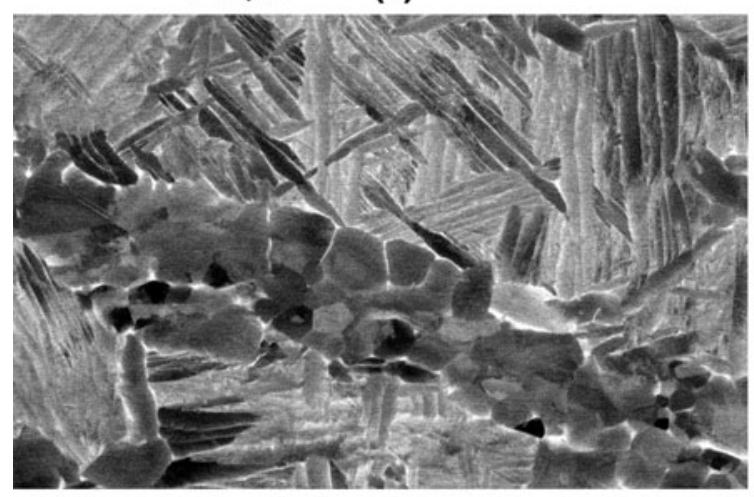

$5 \mu \mathrm{m}$ (c)

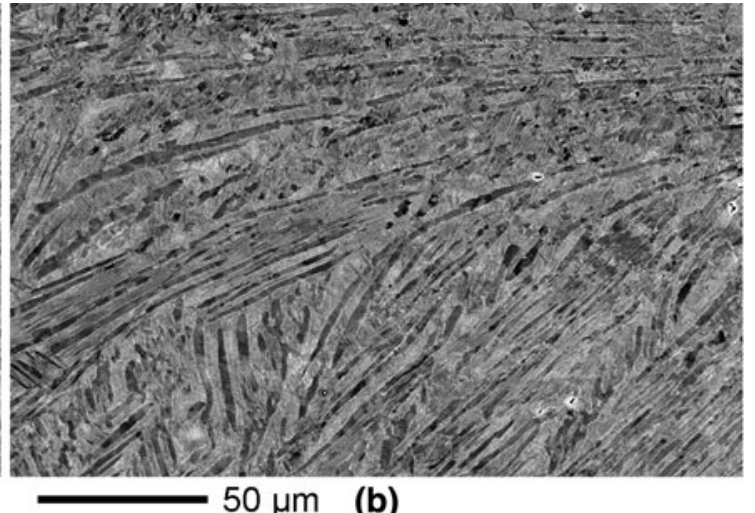

(b)

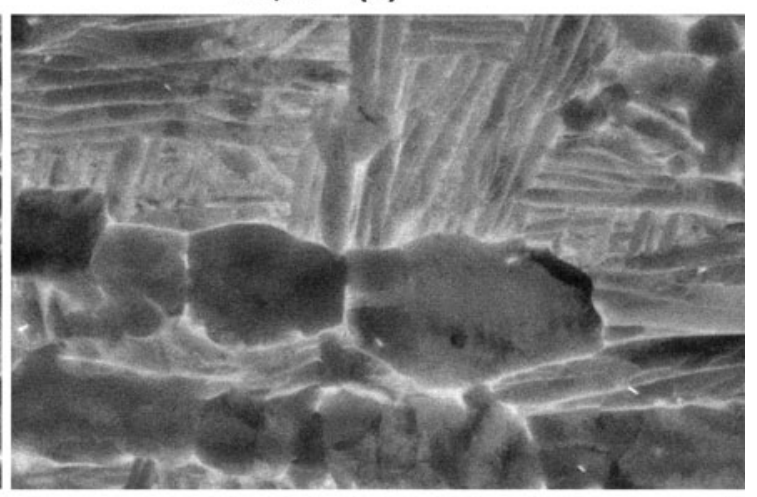

(d)

Fig. 6 - (a) and (b) Typical transverse cross sections from the transition zone in the $\beta$ friction stir processed condition on the advancing side showing a higher volume fraction of transformed $\beta$ compared to the subtransus processed conditions. $(c)$ and $(d)$ Higher magnification images showing the typical substructure within individual $\alpha$ lamellae surrounded by transformed $\beta$. 


\section{Transition zone analysis}

An EBSD scan collected from the region of the transition zone depicted in Figure 5 is shown in Figure 7. Higher resolution scans, $50 \times 50 \mu \mathrm{m}$ each, were acquired at the locations designated (a) through (e). This entire scan was contained within one prior $\beta$ grain. An image quality (IQ) overlay was used on the orientation map to show the difference in EBSD pattern quality between the stir zone and the lamellar structure and the adjacent stir zone. The IQ parameter can be used as a qualitative indication of the amount of residual plastic strain (stored work) present in a particular region of the microstructure, ${ }^{[24]}$ which appears greater in the stir zone compared to the transition zone. This observation is consistent with the presence of remnant dislocations in the fine $\alpha$ grains. It is also recognized that the fine grain size could have also contributed to the low IQ, since there were many $\alpha / \alpha$ boundaries that increased the probability that two different grains contributed to the pattern resulting in a low IQ parameter, although the IQ was also relatively low at the grain interiors, which were sampled during collection of the higher resolution scans at regions (a) through (d) in Figure 7.

Examination of the EBSD data reveals that the first evidence of plastic strain was observed at colony boundaries deep in the transition zone, particularly those with orthogonal basal planes. There was a complex network of sub-boundaries developed within $\alpha$ lamellae and also between the primary $\alpha$ laths and the secondary $\alpha$ that precipitated within the $\beta$ phase due to the thermal cycle (Figure 7, region (a)). When the latter adopted the same variant of the Burgers orientation relationship as the adjacent primary $\alpha$ lath, there were usually small misorientations in the range of 3 to $5 \mathrm{deg}$, suggesting that there was preferential deformation of the $\beta$ phase at these locations. With decreasing distance from the stir zone, there was evidence of low-angle boundary formation across the $\alpha$ lamellae as well as between adjacent lamellae in the same colony. This was most evident at the edge of the transition zone, like that shown in Figure 7 (region (c)). Low-angle boundaries ( $<15 \mathrm{deg})$ only accounted for about 17 pct of the total boundary length measured in this region, and increasing the tolerance to $30 \mathrm{deg}$ increased this number by about $8.5 \mathrm{pct}$. Thus, $\sim 75 \mathrm{pct}$ of the total boundaries in this region had misorientation greater than $30 \mathrm{deg}$ and more than 80 pct of the total boundary length could be classified as high angle. The number of boundaries and the misorientation across the boundaries seemed to depend both on initial colony orientation and the local neighborhood. The orientation effect will be addressed later in more detail; however, no definitive trends were identified for the neighborhood effect.

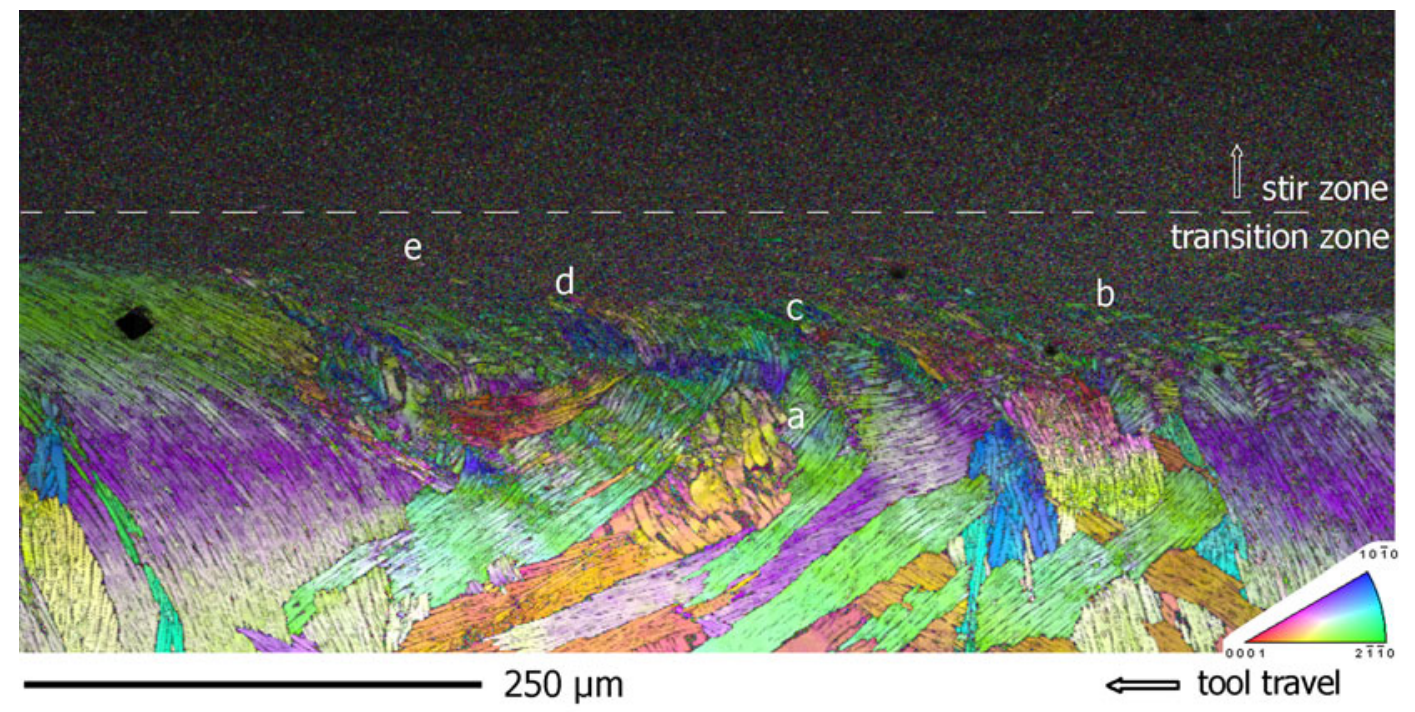

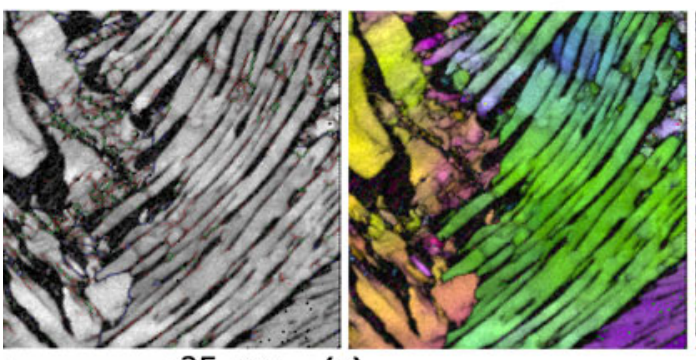

$25 \mu \mathrm{m}$ (a)

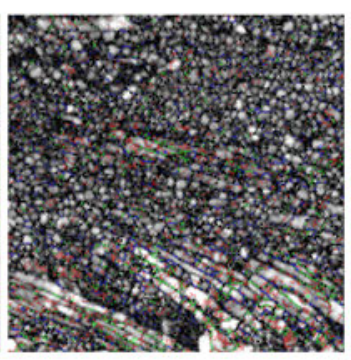

(c)

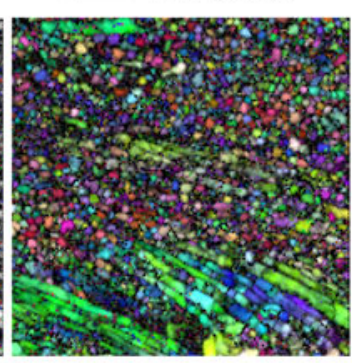

Fig. 7-Longitudinal section through $\alpha / \beta$ friction stir processed plate (A4-100, 1- $\mu \mathrm{m}$ step size). The orientations are colored according to the unit triangle with respect to the tool travel direction. Regions $(a)$ through $(e)$ are locations where higher resolution EBSD scans were collected (the text provides more details). Regions (a) and (c) are shown here with boundaries between adjacent pixels colored according to misorientation angle: red: 2 to $5 \mathrm{deg}$, green: 5 to $15 \mathrm{deg}$, and blue: $>15 \mathrm{deg}$. The dashed line indicates the delineation between the transition zone and stir zone. (Color figure online). 
The orientation distribution and pole figures calculated from the stir zone only portion of Figure 7 (not shown) had a maximum intensity of about 2.0 and 1.4 times random, respectively, indicating that microstructure refinement and complete randomization of grain orientations occurred over a distance of approximately $200 \mu \mathrm{m}$. This implies that there was a steep strain gradient in the transition zone. The pole figures calculated from the high-resolution EBSD scans identified in Figure 7 are shown in Figure 8. The strength of the texture decreased with increasing distance traveled by the friction stir tool inside one prior $\beta$ grain. Despite the lack of a strong texture, closer inspection of the pole figures revealed that there were diffuse intensities located near the B and Y fibers with respect to the local simple shear reference frame in Figure 9. The location of the fibers in orientation space, which were determined by Beausir et al..$^{[46]}$ using polycrystal plasticity simulations, depends only on crystal symmetry and the applied strain path. In other words, the material response to the applied deformation cannot be accounted for by the simple shear deformation imposed by the rotation of the tool, as it frequently can be inside the stir zone. ${ }^{[45,47]}$ The observed texture, however, is consistent with simple shear imposed by the tool translating over colonies that are constrained by the unaffected base material beneath them, i.e., if one assumes the local shear direction is parallel to the tool travel direction and the shear plane normal points toward the retreating side. This is similar to the formation of simple shear textures during sliding contact of metals. ${ }^{[48]}$ The maximum intensities for regions (a) and (b) were greater because there was remnant lamellar structure that was not yet spherodized. The colonies that were among the last to be spherodized had their $c$-axes perpendicular to the tool rotation axis and also had $\langle a\rangle$ directions nearly aligned with the tool travel direction. This is near the $\mathrm{B}$ component with respect to the simple shear reference frame induced by the tool translation in this location. This was a typical result in the sense that colonies that were in or near one
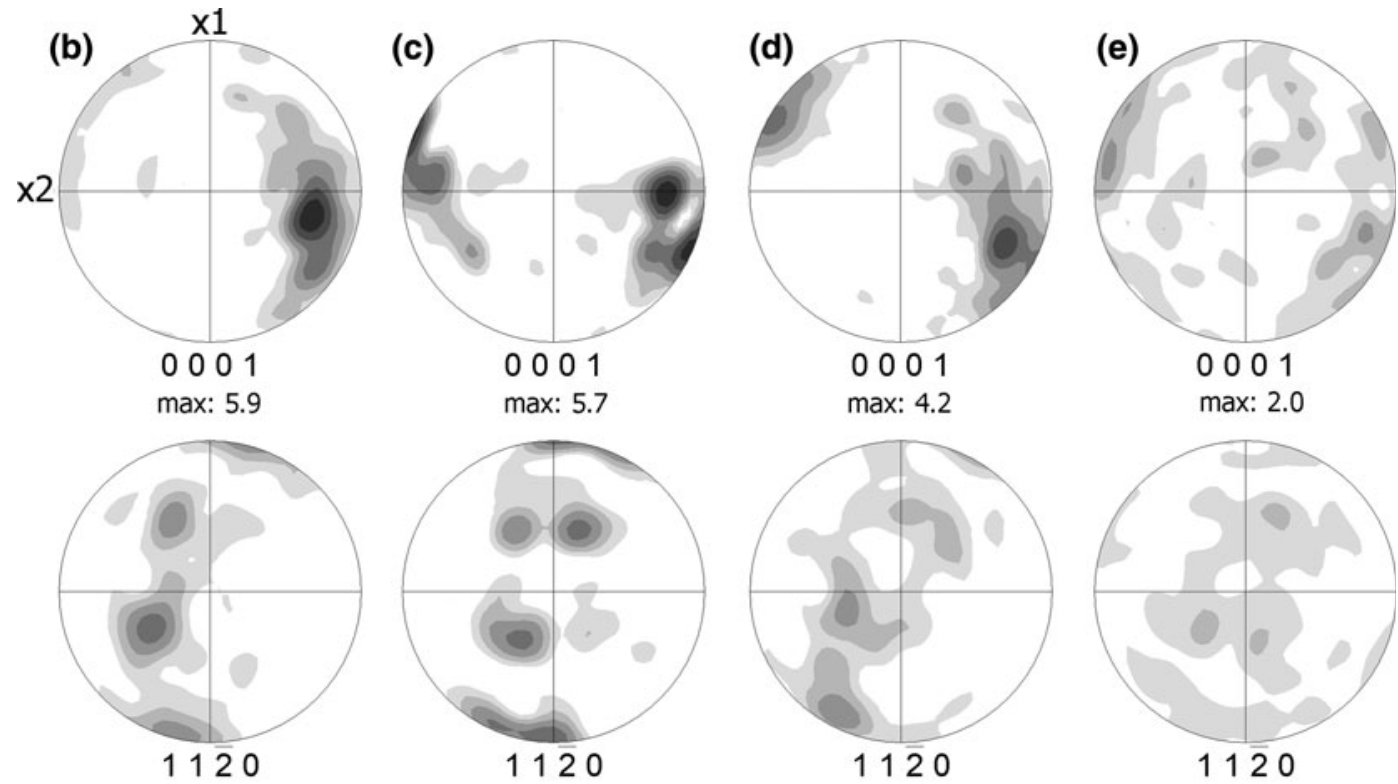

Equal area projections, scale: $<1.0,1.4,1.8,2.5,3.3,4.5,6.0$

Fig. $8-0001$ and $11 \overline{2} 0$ pole figures for regions (b) through (d) in Fig. 7 depicting texture evolution along the stir zone/transition zone interface with increasing distance traveled by the tool in one prior $\beta$ grain.
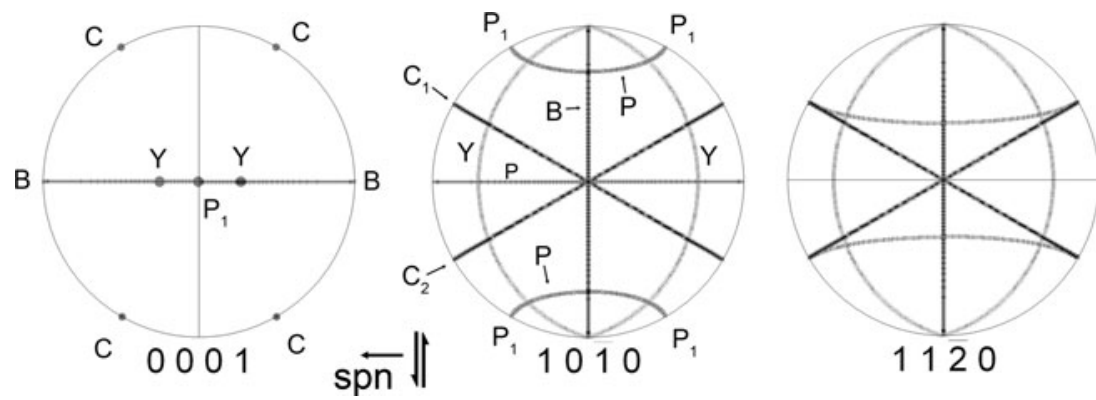

Fig. 9-Locations of fibers for simple shear deformation of materials with hexagonal symmetry in equal area projection. The positions of the fibers in the $11 \overline{2} 0$ pole figure are the same as in $10 \overline{1} 0$ except that the point $\mathbf{P}_{1}$ intersects the $\mathrm{C}_{1}$ and $\mathbf{C}_{2}$ fibers on the circumference of the projection. 
of the ideal orientations tended to be more resistant to recrystallization compared to colonies in nonideal orientations, which is a characteristic of continuous recrystallization and extended recovery processes. ${ }^{[21]}$ This is most likely related to the fact that colonies in nonideal orientations have larger lattice rotation rates and thus would be expected to accumulate stored energy faster than those in ideal orientations.

A benefit of using a coarse colony starting structure for studying the recrystallization mechanisms active during FSP or FSW was that an entire colony was not necessarily consumed by the advancing tool. Thus, there were often colonies where one side was completely unaffected by the deformation imposed by the friction stir tool, while the other side exhibited significant lattice rotation until it was refined to micron-sized equiaxed grains. Due to the higher volume fraction of transformed $\beta$ in the $\beta$ friction stir processed condition (greater mean $\alpha$ lath spacing), it was easier to track individual lamellae from the undeformed state through the transition zone until they were spherodized and indistinguishable from neighboring laths. Thus, a transverse cross section of the $\beta$ friction stir processed condition was prepared for EBSD. The resulting EBSD map from the advancing side transition zone is shown in Figure 10. Although not shown here, reconstruction of the parent $\beta$ grain orientations confirmed that the entire scan was contained within the same prior $\beta$ grain. In order to study the effect of colony orientation on spherodization of the lamellar microstructure, the orientations of the $\alpha$-phase points belonging to the four colonies identified in Figure 10 were extracted from the EBSD data set. The orientations were then rotated about the principal axes of the sample reference frame to plot them in a more intuitive reference frame with respect to the tool rotation axis and travel direction (Figure 11). Examination of the pole figures reveals that orientation gradients were present in all of the colonies; however, there was significantly more lattice rotation prior to spherodization in some colonies as opposed to others. In colonies 2 and 4, for example, there was nearly $50 \mathrm{deg}$ of lattice rotation, while colonies 1 and 3 merely became more diffuse about a mean orientation without significant change in $c$-axis orientation.

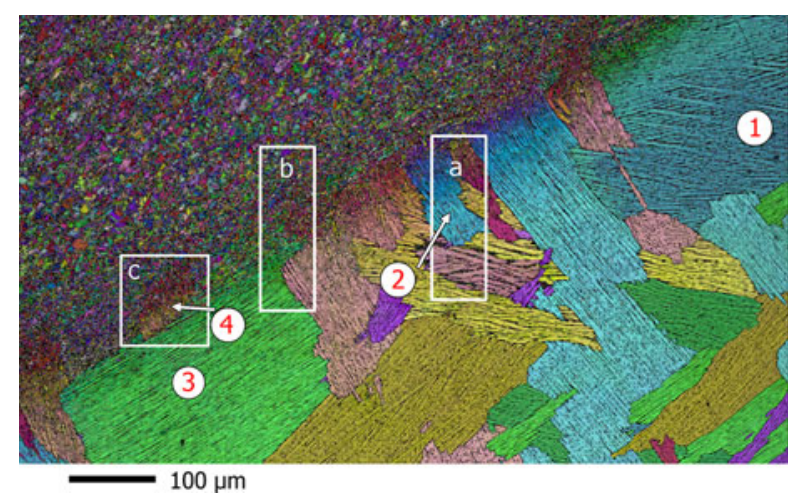

Fig. 10-Inverse pole figure map (with respect to the tool rotation axis, up in this image) with IQ overlay of the advancing side transition zone in the $\beta$ friction stir processed condition. (Color figure online).
The difference in response to the applied deformation among the colonies can be partially explained by considering the orientation of each colony with respect to the local simple shear reference frame. Most studies consider what happens to a material element at a particular location or one that travels with the rotating simple shear reference frame. ${ }^{[45,47,49,50]}$ However, in order to study the transition zone, it is necessary to understand the change in the local deformation state at a constant position in the plate as the tool passes over it. It is generally accepted that a state of simple shear can be imposed by either the shoulder or the pin $^{[51]}$ and that the taper of the pin affects the orientation of the local shear plane ${ }^{[50,52]}$ In the present study, the pin had a 30 deg taper relative to the shoulder, which is approximately equal to the slope of the stir zone transition zone border in Figure 10, which could imply that this would coincide with the local shear plane. However, the location at which these data were collected (identified in Figure 11) was sufficiently far from the pin and near enough the surface that the shoulder of the tool would be expected to be the dominant factor influencing deformation behavior. Assuming that the shear direction is parallel to the tangent to the tool at all radial positions (not only at the periphery of the tool), the advancing side transition zone experienced a continually evolving shear reference frame as the friction stir tool passed over it (Figure 11). This appears to be a good assumption based on the finite element and crystal plasticity work of Cho et al. ${ }^{[49,53]}$ and the experimental work of Ahmed et al. ${ }^{[45]}$ for pin-induced material flow. However, due to the short, small diameter pins used in the present study, it is believed that the local shear plane, at least for this location, is governed by the shoulder-induced material flow. In other words, the shear plane normal was perpendicular to any point on the circumference of the tool, and the shear direction is always acting tangent to concentric circles originating at the tool rotation axis.

Considering the simple shear reference frame described previously, colony 1 was the only one that had its basal plane near the shear plane and was thus the only colony that was oriented for easy basal slip. From its initial orientation, there was approximately a $15 \mathrm{deg}$ rotation of the basal pole as this colony was spherodized. On the other hand, colony 2 has its basal pole nearly aligned with the shear direction and so the local shear was imposed parallel to the $c$-axis. In this orientation, the colony is not near an ideal orientation and, furthermore, must deform by $\langle c+a\rangle$ slip in order to rotate. Since the $\langle c+a\rangle$ slip systems have higher critical resolved shear stress ${ }^{[30]}$ than either basal or prism $\langle a\rangle$ slip, colony 2 is considered to be in a crystallographically "hard" orientation with respect to the local simple shear stress state and is, thus, more difficult to spherodize. This sort of orientation dependence was also noted under more simple deformation modes, like upset forging, ${ }^{[24]}$ and is the primary cause for the formation of large microtextured regions. Such anisotropy at the single colony scale has been documented by Salem and Semiatin $^{[54]}$ during axisymmetric compression of single colonies of Ti-6-4 at $1088 \mathrm{~K}\left(815^{\circ} \mathrm{C}\right)$. 


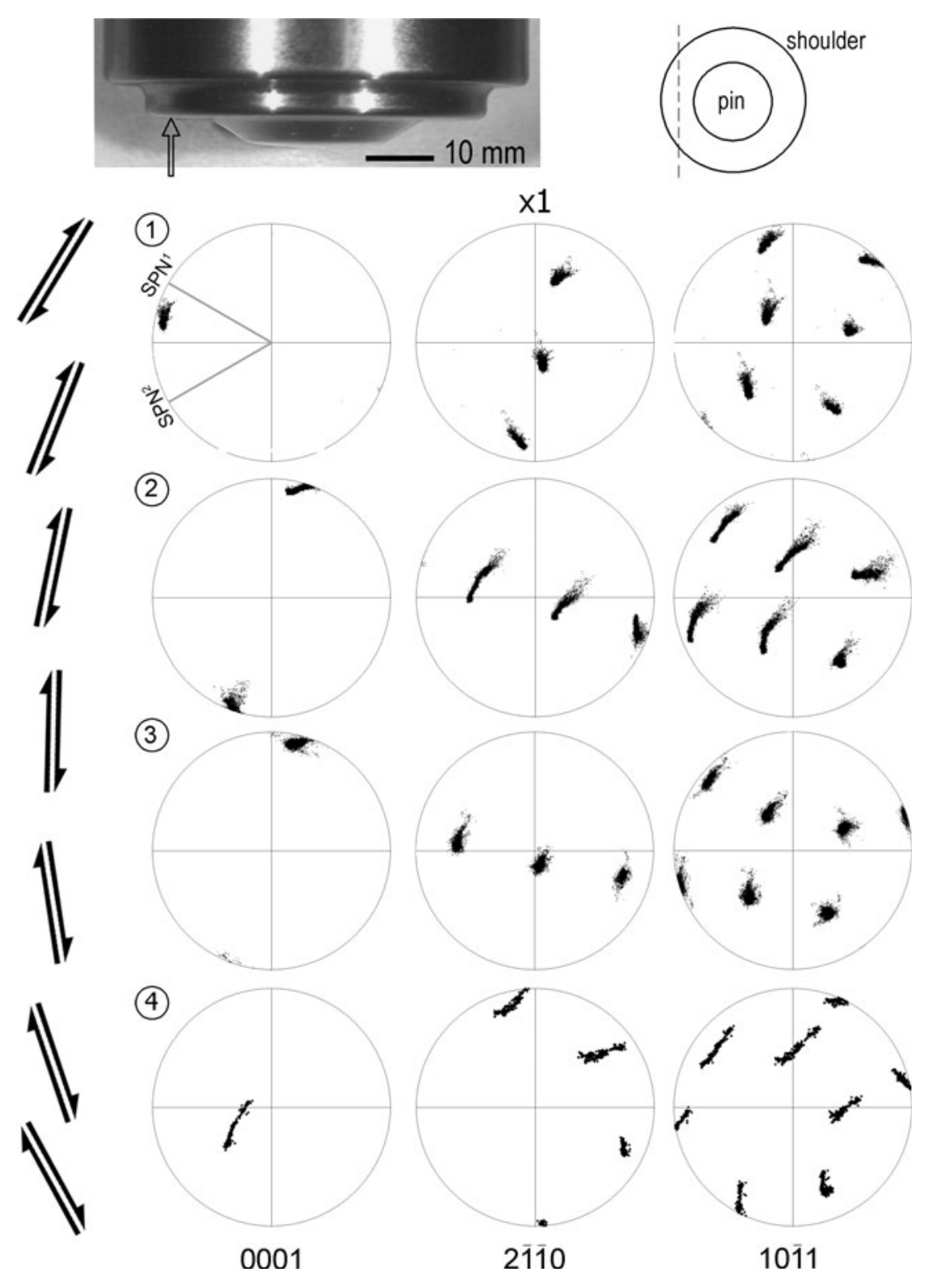

Fig. 11-Discrete equal area $\alpha$-phase pole figures showing the orientation gradients present in the individual colonies marked in Fig. 10. The tool travel direction is up (parallel to $\times 1$ ) and the tool is rotating clockwise about the direction normal to the plane of the projection. The range of shear plane normal directions experienced in this region as the tool passes are designated by $\mathrm{SPN}^{1} \rightarrow \mathrm{SPN}^{2}$. The shear direction is also shown (schematically) at several times at which the tool would be passing over it. The location of the scan with respect to the tool geometry in transverse cross section is denoted by the arrow while it is shown schematically in plan view.

The initial $\alpha$ colony orientations alone, however, could not account for the observed behavior because the initial orientation of colony 3 is related to that of colony 2 by a rotation of $10.5 \mathrm{deg}$ about [0001], and yet it responded completely differently to the applied deformation. There was substantially more lattice rotation prior to spherodization in the latter compared to the former. This can be rationalized by considering the difference in orientation of the $\alpha / \beta$ interfaces with respect to the local stir zone/transition zone interface. The $\alpha / \beta$ interfaces of colonies 2 and 3 are perpendicular and parallel to the stir zone/transition zone interface, respectfully. At first, such a large morphological change for a small change in crystallography might be counterintuitive; however, TEM analysis by Bhattacharyya et al. ${ }^{[55]}$ showed that an angle of $\sim 81$ deg exists between the $\alpha / \beta$ interfaces of colonies that share a common basal plane (when viewed along [0001]). This is also in agreement with measurements made with EBSD by the present authors. When the $\alpha / \beta$ interfaces were oriented perpendicular to the local stir zone/transition zone interface, the laths tended to bend toward the direction of material flow (colony 2), similar to what was described earlier (Figure 7). Conversely, when the $\alpha / \beta$ interface was nearly parallel to the stir zone/transition zone interface, no bending was observed, the transition zone was narrower, and there was a smaller amount of lattice rotation prior to spherodization (colony 3). While several studies have cited the crystallographic dependence of the $\alpha$ phase on recrystallization 
behavior ${ }^{[24,32,33]}$ the present results suggest there is a morphological dependence as well that has not been previously recognized.

In order to investigate microstructure evolution over the orientation gradients, scans with $0.35-\mu \mathrm{m}$ resolution were acquired from the regions, labeled (a) through (c) in Figure 10. The resulting EBSD maps and IQ maps with color-coded boundaries for regions (a) and (b) are shown in Figure 12. In region (a), four colonies increasingly closer to the stir zone were identified. The boundary maps reveal an interesting trend with decreasing distance from the stir zone. In colony 1, the furthest from the stir zone, there were no local pixel-to-pixel misorientations greater than $2 \mathrm{deg}$. Colony 2 contained several low-angle boundaries ( 2 to $5 \mathrm{deg}$ ) parallel to the $\alpha / \beta$ interfaces and also a few boundaries with higher misorientation where it bordered colony 4 . There were low-angle boundaries across the $\alpha$ lamellae in colony 3 and similar substructure in colony 4; however, the density of colony boundaries across the lamellae increased substantially in the latter. In addition, there were several locations within colony 4 , where an entire segment of the lath is completely surrounded by a boundary with misorientation between 2 and $15 \mathrm{deg}$. These subgrains have diameters on the order of 1 to $1.5 \mu \mathrm{m}$, which is consistent with the size of the equiaxed grains observed in the higher strained regions of the transition zone. The diameter of the spherodized $\alpha$ grains was limited by the width of the host $\alpha$ lamellae, and there was no evidence to suggest that subgrain coarsening or boundary migration occurred. This can be attributed to two factors. First, the relatively low misorientation across the $\alpha / \alpha$ boundaries formed within the laths during the early stages of deformation offers little driving force for migration in one direction; and second, the presence of $\beta$ phase inhibits outward migration of the $\alpha / \alpha$ boundary due to the large composition difference between the $\alpha$ and $\beta$ phases.

The formation of subgrains can be shown semiquantitatively through the use of misorientation distributions along individual lamellae in colonies (1) through (4) (Figure 13(a)). This type of plot reveals the crystallographic misorientation of each point along a line profile in the EBSD data set relative to the first point chosen. Fonda et al. ${ }^{[56]}$ have used a similar approach to study the evolution of microstructure in the transition zone of Al-2195 friction stir welds. The distributions from Ti-6-4 shown in Figure 13 were typical among several examined by selecting the orientations along line profiles of random lamellae within each of the four colonies. With decreasing distance from the stir zone, there was always a concomitant increase in the maximum misorientation and often an increase in the local point-topoint misorientation. Considering that there were no

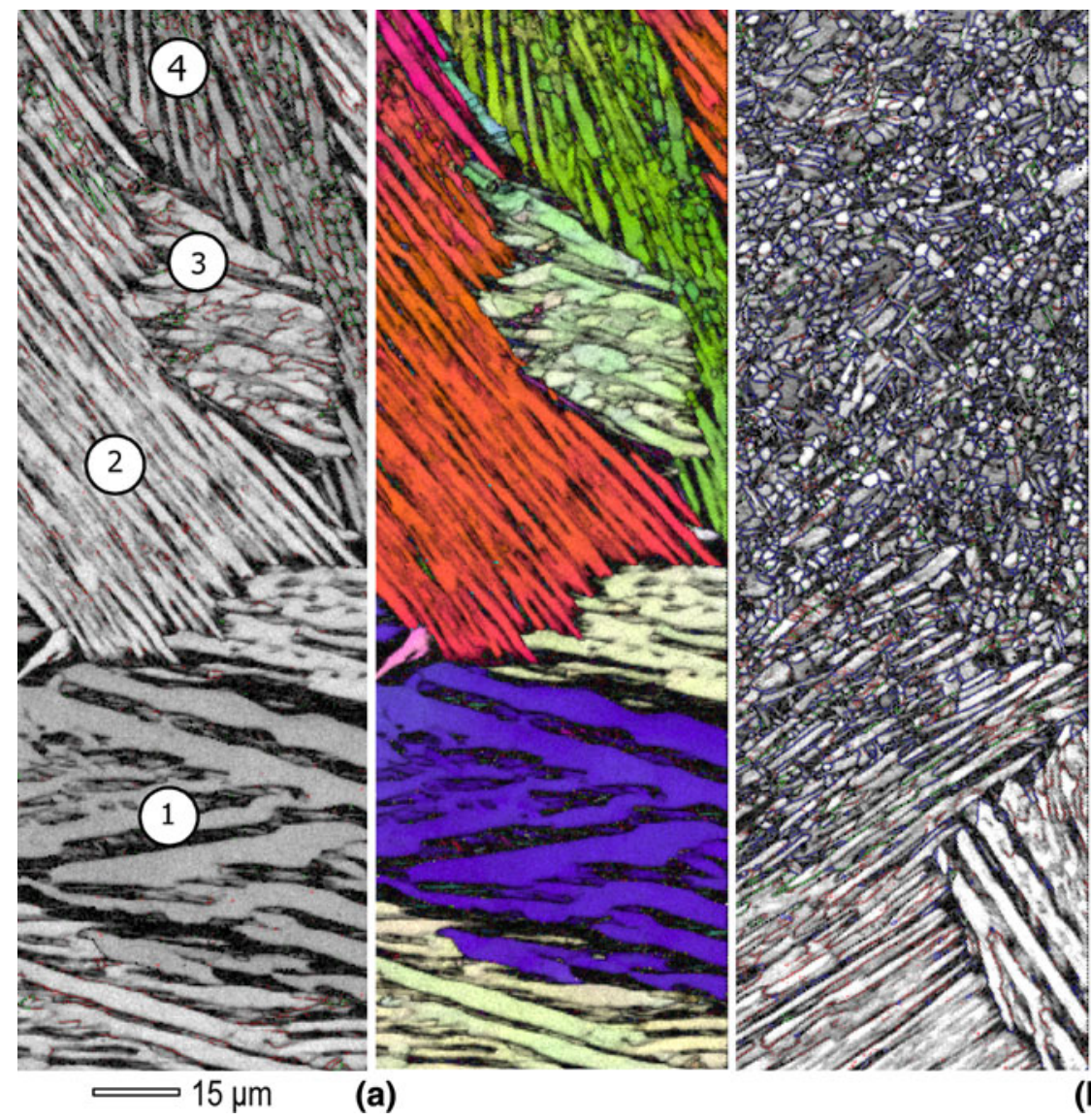

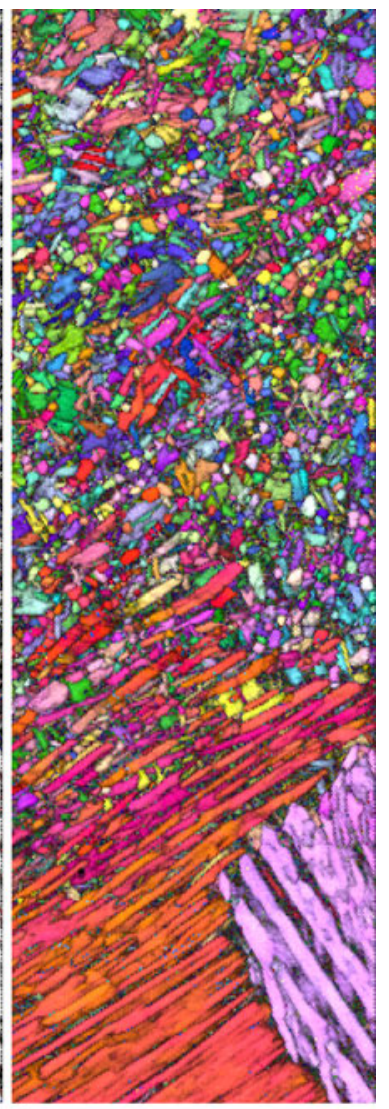

(b)

Fig. 12-IQ and IQ + inverse pole figure colored maps of regions (a) and (b) in Fig. 10. Boundaries were color coded relative to their misorientation angles according to the scheme used in Fig. 7. (Color figure online). 


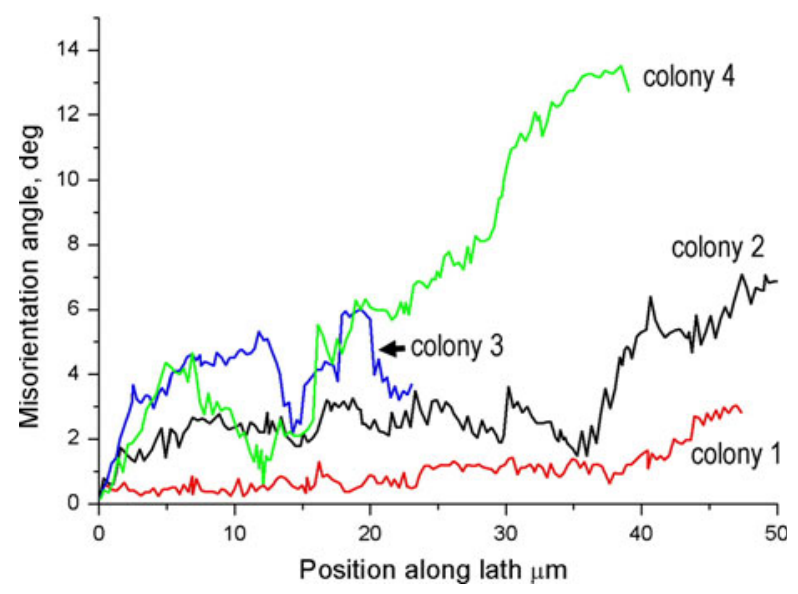

Fig. 13-Crystallographic misorientation profiles along individual lamellae in colonies 1 through 4 in Fig. 12.

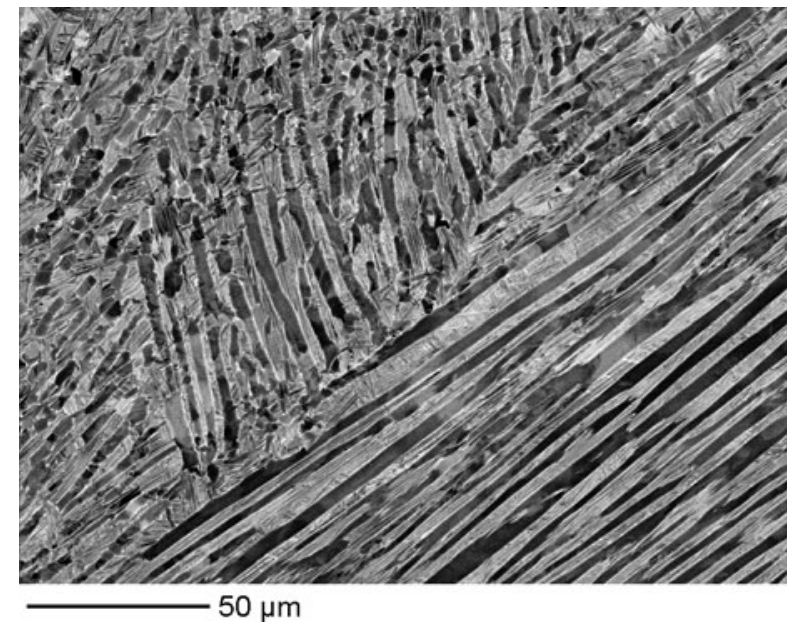

Fig. 14-Backscattered electron image of the microstructure corresponding to region (c) in Fig. 10.

dislocations present in the base material, they must have been introduced by FSP.

A backscattered electron image of the microstructure at location (c) in Figure 10 is shown in Figure 14. In this region, there was significant narrowing of the $\alpha$ lamellae resulting in an increase in the volume fraction of $\beta$ phase at temperature. Here, the dark phase is the primary $\alpha$, while the lighter regions are the regions of transformed $\beta$ that is made up of fine $\alpha+\beta$ lamellae. The EBSD scan from the same location (Figure 15) reveals that much of the secondary $\alpha$ has adopted the same variant of the Burgers orientation relationship as the adjacent primary $\alpha$ lamellae. Although the same variant was adopted, there were small angular misorientations between the primary and secondary $\alpha$ leading to small changes in color in the EBSD maps. This implied that there was nonuniform strain partitioning within the transition zone during processing. Moreover, this proves that the $\beta$ phase had not yet been recrystallized in this region. Similarly, the primary and secondary $\alpha$ in many of the colonies in Figure 12 are separated by low-angle boundaries, so the $\beta$ phase had not recrystallized there either.
However, at locations nearer the stir zone, such as the red colony in Figure 12, region (b), the secondary $\alpha$ has adopted multiple variants of the Burgers orientation relationship. This can account for many of the highangle boundaries in this part of the colony that are present on the IQ map that are not observed in region (b). There is a multitude of boundaries with a misorientation angle exceeding $15 \mathrm{deg}$ in the neighboring stir zone of both regions. Three types of boundaries are possible and all were identified: equiaxed $\alpha /$ equiaxed $\alpha$, equiaxed $\alpha /$ secondary $\alpha\left(\alpha_{s}\right)$, and $\alpha_{s} / \alpha_{s}$ boundaries. The $\alpha_{s} / \alpha_{s}$ and equiaxed $\alpha / \alpha_{s}$ boundaries form during cooling after the tool passes and there is subsequent nucleation and growth of colony $\alpha$. The equiaxed $\alpha /$ equiaxed $\alpha$ boundaries, on the other hand, arise from the gradual increase in subgrain boundary misorientation inside individual $\alpha$ lamellae. This is evident on the misorientation distributions from individual lamellae reported in Figure 16. The misorientations in these lamellae are substantially larger than those observed in the colonies in region (a), which did not directly border the stir zone. The slopes of the lines reveal that there is a steep misorientation gradient with rotations between 0.75 and $1.25 \mathrm{deg} \mu \mathrm{m}^{-1}$. The orientations along these line profiles were used to generate the equal area projections in Figure 15. This plot reveals that, in addition to the crystallographic and morphological dependence observed at the single colony length scale, individual lamellae within a colony also have unique responses to the applied deformation. These phenomena all contribute to the elimination of the aligned lamellar structure in favor of the nearly random distribution of fine equiaxed grains in the adjacent stir zone.

In the subtransus processed condition, the texture of the $\alpha$ phase in the stir zone adjacent to the transition zone exhibited a weak simple shear deformation texture. In contrast, this location consisted solely of $\beta$ phase during processing above the $\beta$ transus. During subsequent cooling, the $\beta$ phase transformed to $\alpha$ by nucleation and growth resulting in a transformation texture being created in this region. The texture of the $\alpha$ and $\beta$ phases calculated from the orientations in the stir zone portion of Figure 10 are shown in Figure 17. The texture of the $\beta$ phase in the transition zone could be correlated to a bcc simple shear texture. Examination of the orientation distribution function (ODF) (not shown) revealed that the texture consisted primarily of orientations along the $\{h k l\}\langle 111\rangle$ partial fiber. These were primarily $\{011\}\langle 1 \overline{1} 1\rangle(\mathrm{E} 1 / \mathrm{E} 2)$ orientations, with an intensity of 9.8 times random, and the D2(112) [ $\overline{1} 11]$ component, which had an intensity of approximately 4 times random. Previous studies ${ }^{[14,50]}$ have identified the $\mathrm{D} 2$ and $\overline{\mathbf{J}}(\overline{1} \overline{1} 0)[\overline{1} 1 \overline{2}]$ texture components in regions of the stir zone that were directly affected by the tool. However, the strains are expected to be somewhat lower near the transition zone in locations that were not directly affected by the pin, which could account for the difference in texture. It is interesting to note that these same components, E1, E2, and D2, were observed by Baczynski and Jonas ${ }^{[57]}$ in bcc iron deformed in hot torsion at $840{ }^{\circ} \mathrm{C}$. The intensities of the E1/E2 components remained constant at 10.3 times random through 


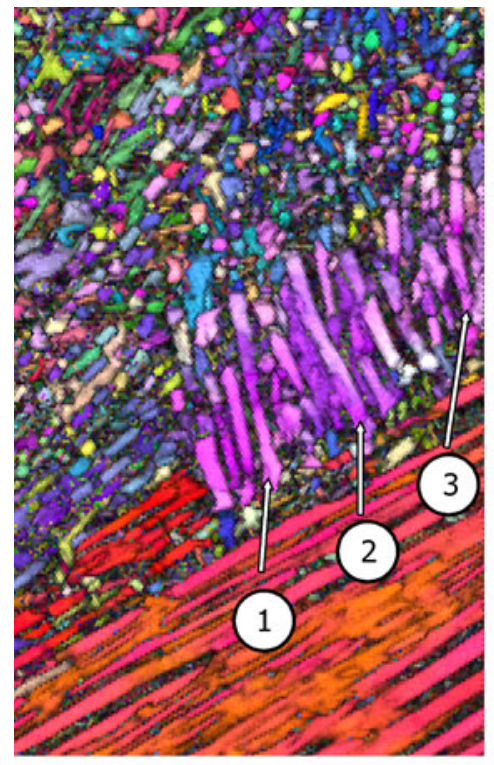

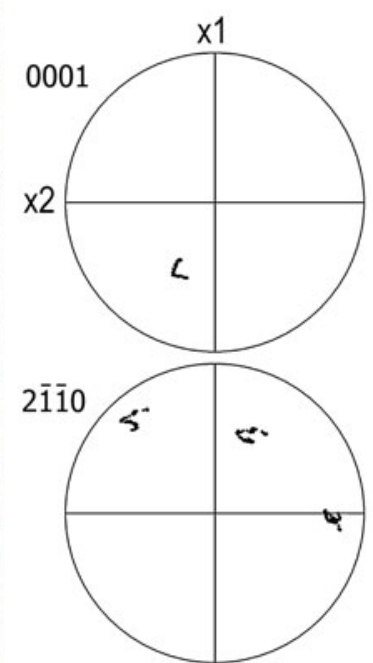

lath 1
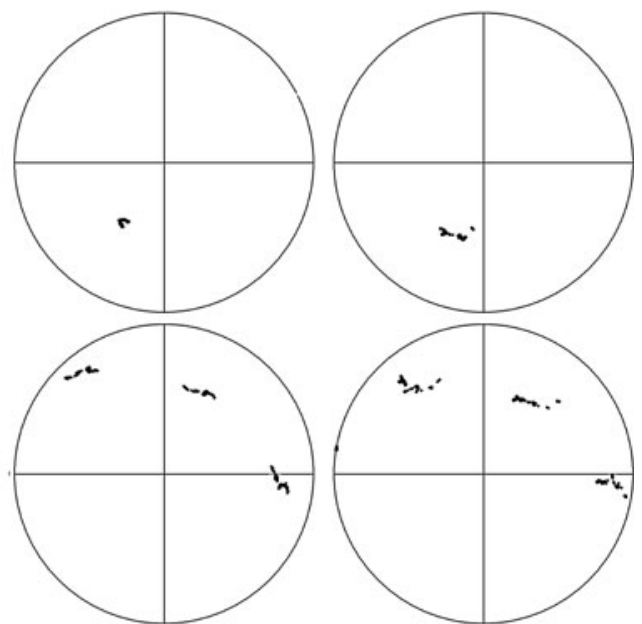

lath 2

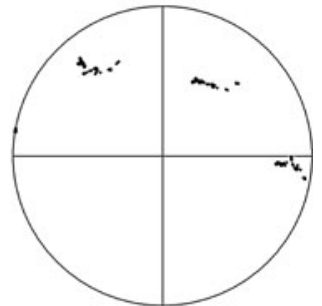

lath 3

Fig. 15-EBSD map of region (c) in Fig. 10. The pole figures show the response of individual lamellae within the same colony. The tool travel direction is parallel to $\times 1$ and the tool is rotating clockwise about the direction normal to the plane of the projections. (Color figure online).

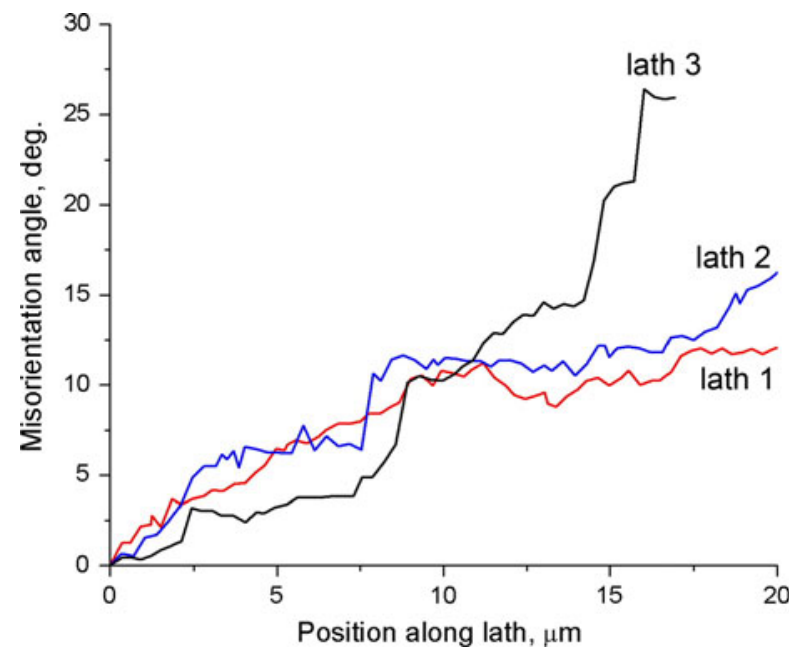

Fig. 16-Crystallographic misorientation profiles along $\alpha$ laths (1) through (3) identified in Fig. 15.

a strain of 4.9 , while the D2 was slightly favored at lower strains (14.1 times random) and was extremely favored at larger strains (maximum intensity of 47 times random at a strain of 4.9). With regards to the $\alpha$-phase transformation texture, the 0001 pole figure has one moderate intensity peak of about 5.3 times random along with several lower intensity peaks in the 2 to 3 times random range, which coincided well with the $\beta$ phase peaks in the calculated texture.

\section{Stir zone texture during subtransus FSP}

The size of the $\alpha$ subgrains formed deep in the transition zone were approximately the same size as the equiaxed grains found in the stir zone adjacent to the transition zone as well as those equiaxed grains that
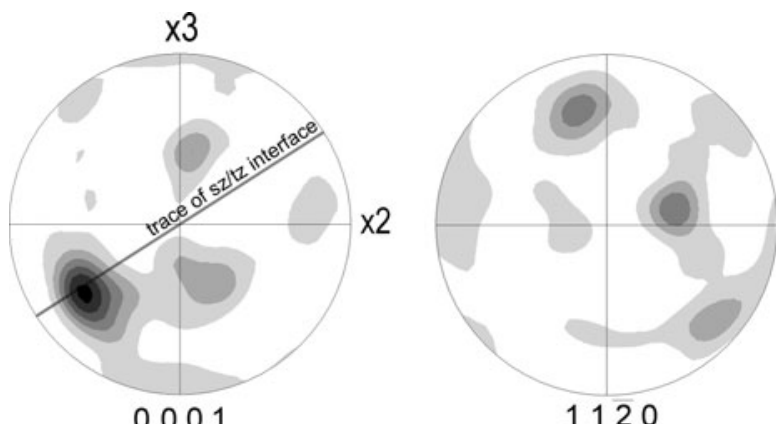

Equal area projections, scale: $<1.0,1.8,2.6,3.4,4.2,5.0$

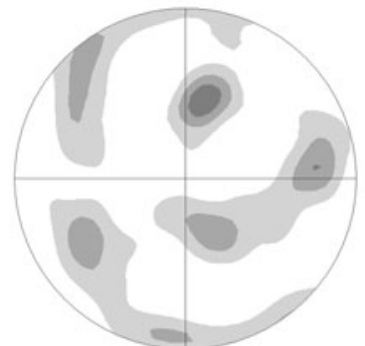

011

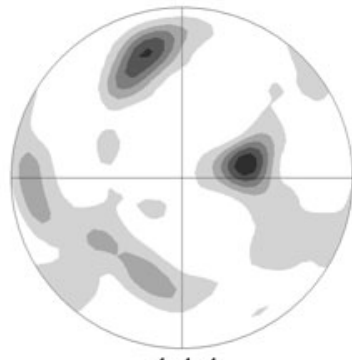

111
Equal area projections, scale: $<1.0,1.7,2.4,3.1,3.8,4.5$

Fig. 17- $\alpha$-phase pole figures depicting the texture of the stir zone region of Fig. 10. The tool rotation axis is parallel to $\times 3$, while the advancing side is parallel to $\times 2$ and the tool travel direction is out of the plane of the image. The trace of the stir zone/transition zone interface is also shown on the 0001 pole figure.

were present in the final stir zone microstructure. The grains were shown to originate by a gradual increase in $\alpha / \alpha$ boundary misorientation within individual laths as they entered the shear zone ${ }^{[58]}$ ahead of the friction stir tool until they were completely surrounded by high-angle boundaries. The grains were shown to be 
essentially free from preferred orientation. Once developed in the transition zone, the $\sim 1-\mu \mathrm{m}$ grains that were separated by high-angle boundaries persisted into the stir zone and were observed at all locations examined. No microtextured regions, such as those typical of $\alpha+\beta$ forged products, were found within the stir zone.

The central stir zone textures were calculated using the spherical harmonic method ${ }^{[59]}$ and are presented on equal area projections in Figure 18. These data were calculated from EBSD scans consisting of approximately $55,000(\alpha / \beta)$ to 60,000 (high $\alpha / \beta)$ grains and, thus, represent large areas compared to the constituent size. The data were collected at approximately the midplane of the stir zone. The maximum intensity in both sets of pole figures was low, only $\sim 2.6$ and $\sim 3.1$ times random for the high $\alpha / \beta$ and $\alpha / \beta$ conditions, respectively. In the ODF (not shown here), the maximum intensities were 6.0 and 4.8 times random, respectively. The most noteworthy feature is the similarity in texture between the two subtransus processing conditions. Both data sets exhibit the $\mathrm{B}$ and $\mathrm{P}$ partial fibers characteristic of simple shear deformation of materials with hexagonal symmetry. ${ }^{[46]}$ These partial fibers correspond to the basal plane being parallel to the shear plane and the $\langle a\rangle$ directions parallel to the shear direction. Thus, the simple shear textures developed in the transition zone are also present in the stir zone; however, there is one difference. The stir zone textures were dominated by the deformation gradient imposed by the tool rotating; i.e., the local shear direction is parallel to the tangent of the tool, which tends to coincide with one of the $\langle a\rangle$ directions. On the other hand, the transition zone textures seemed to be influenced by the local stir zone/transition zone interface with the local shear direction being parallel to the tool translation direction.

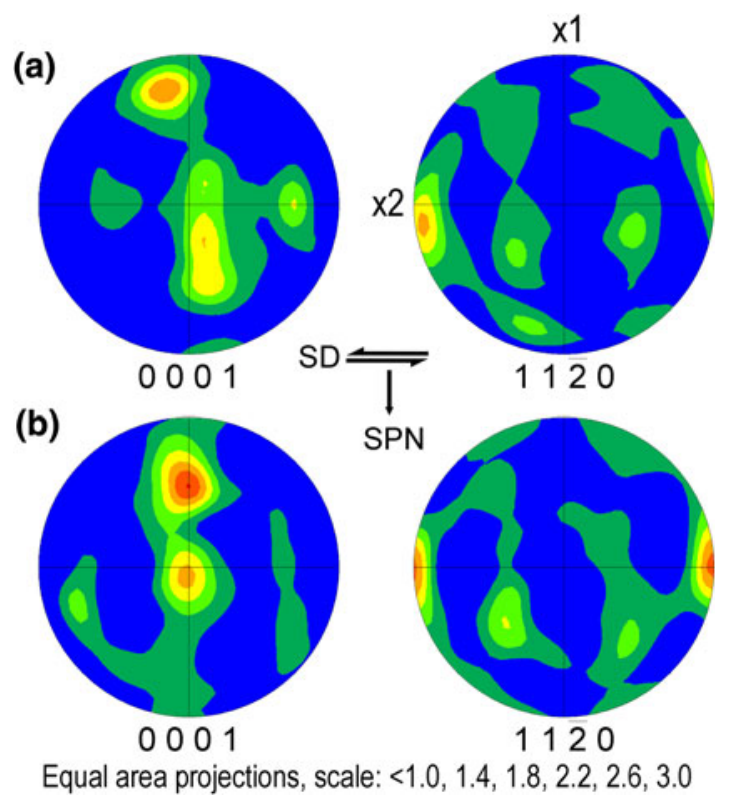

Fig. 18 - Central stir zone texture in the $(a)$ high $\alpha / \beta$ and $(b) \alpha / \beta$ friction stir processed conditions. The tool travel direction is parallel to $\times 1$, while $\times 2$ points to the advancing side. The local shear direction imposed by the tool in this region is parallel to $\times 2$. (Color figure online).
It is noted that the texture in the high $\alpha / \beta$ friction stir processed condition was a combination of a deformation texture (the $\alpha$ grains) and transformation texture (the transformed $\beta$ ); however, these features were on such a small scale that it was not possible to deconvolute the contributions of each to the final texture. Attempts to determine the $\beta$-phase texture resulting from FSP below the $\beta$ transus were not possible because of two complicating factors. First, there was a very small volume fraction of $\beta$ phase present, which resulted in a significantly reduced sampled volume; and second, much of the $\beta$ actually contained multiple variants of fine scale $\alpha$ precipitates that were below the resolution limit of EBSD.

\section{Stir zone texture during $\beta$ FSP}

In material processed above the $\beta$ transus, singlephase $\beta$ was present during processing, which transformed by nucleation and growth of $\alpha$ phase during cooling after the tool had passed and the material was no longer being deformed. Therefore, the measured $\alpha$ phase orientations reflected a transformation texture inherited from the high-temperature $\beta$-phase texture. Thus, it was necessary to reconstruct the parent grain orientations in order to study the state of the material at high temperature, before cooling from above the $\beta$ transus. This was in contrast to previous studies, which inferred the $\beta$-phase texture from the inherited $\alpha$-phase orientations ${ }^{[50]}$ or from limited measurements collected from within the minority $\beta$ phase. ${ }^{[14]}$

The $\alpha$-phase orientations measured with EBSD in the central stir zone, as well as the reconstructed parent $\beta$ grains, are shown in Figure 19. The reconstruction from the $\beta$ friction stir processed specimens confirms that the $\beta$ grains are as fine as suggested by backscattered imaging with an average grain size of approximately $27 \mu \mathrm{m}$. Pole figures for the $\alpha$ and reconstructed $\beta$ phases were calculated and are shown in Figure 20. Comparison of the 0001 and 011 poles as well as the $11 \overline{2} 0$ and 111 poles revealed good correlation between the intensities, which implies the Burgers orientation was maintained and that the reconstruction was successful. The maximum intensity of the $\alpha$-phase pole figures was only about 2.7 times random, while the orientation distribution exhibited a peak of approximately 4.6 times random. In contrast, the $\beta$-phase pole figures had a maximum intensity around 4.6 times random, which lies in the 001 pole figure while the ODF showed a maximum intensity of approximately 9 times random. Considering the 011 and 111 pole figures, the latter has the higher intensity of the two with a peak of 3.8 times random, while the 011 has a maximum of about 2.5 times. The basal poles were distributed quite evenly among the intensities on the 011 pole figure, indicating limited variant selection for the parallel plane aspect of the Burgers orientation relationship. A relatively high density of 001 poles oriented near the shear plane normal and the shear direction was noted which is not a typical shear deformation texture component.

Two partial fibers develop in orientation space during simple shear of a bcc material: the $\{h k l\}\langle 111\rangle$ and the $\{110\}\langle u v w\rangle,{ }^{[60]}$ indexed in the form $\{h k l$ parallel to the 

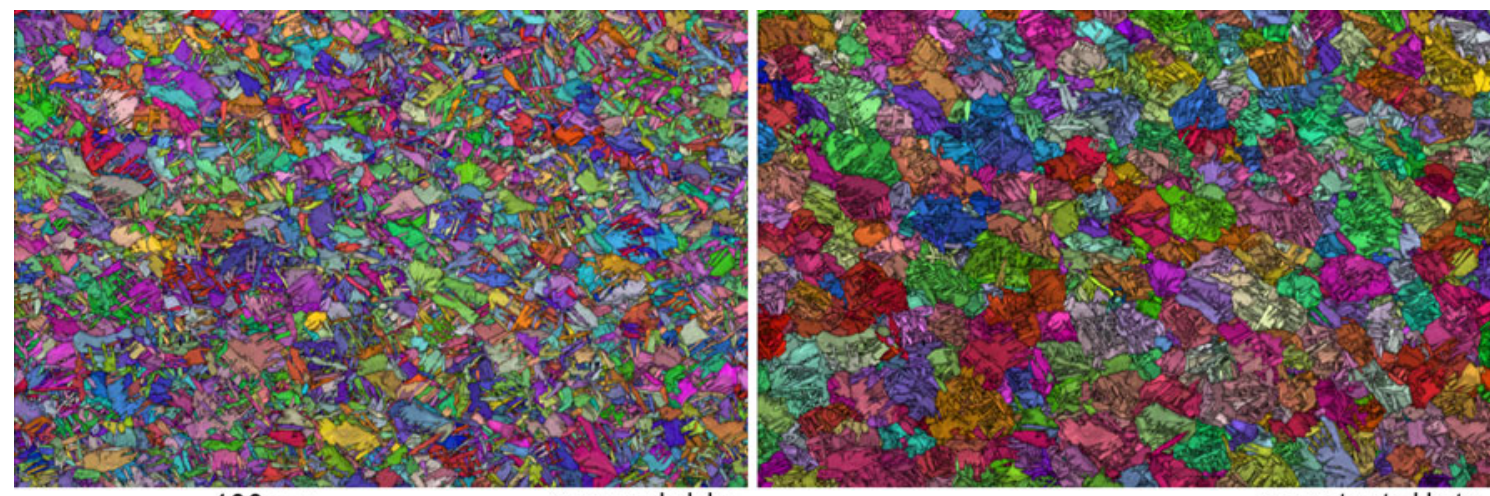

$100 \mu \mathrm{m}$

measured alpha

reconstructed beta

Fig. 19-Inverse pole figure map (with respect to the tool rotation axis) and IQ overlay of the measured $\alpha$ and reconstructed $\beta$ orientations from the central stir zone in the wake of the tool (plan view). (Color figure online).
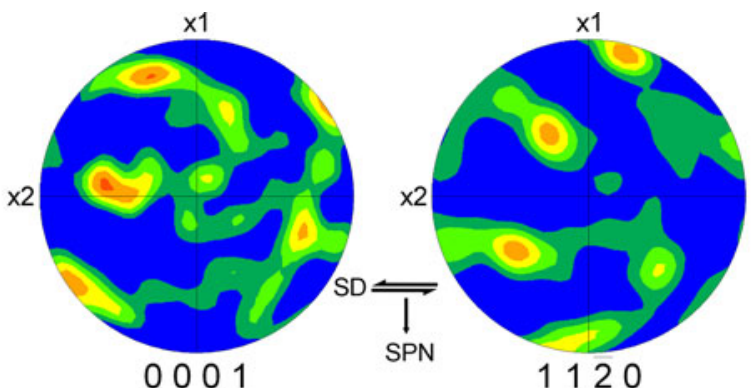

Alpha phase, equal area projections, scale: $<1.0,1.4,1.8,2.2,2.6,3.0$

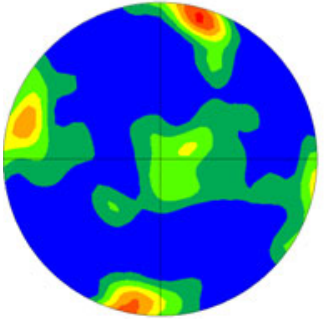

001

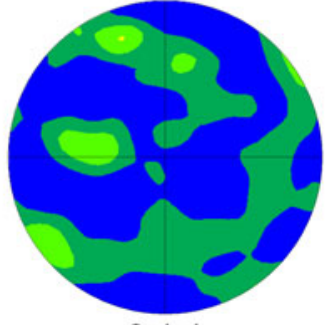

011

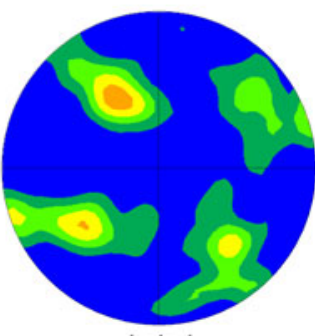

111

Beta phase, equal area projections, scale: $<1.0,1.8,2.6,3.4,4.2,5.0$

Fig. 20-Textures of the $\alpha$ and $\beta$ phases from the orientations shown in Fig. 19. The local shear direction and shear plane normal are designated by SD and SPN, respectively. The tool travel direction is parallel to $\times 1$ while $\times 2$ points to the advancing side. (Color figure online).

shear plane $\langle\langle u v w$ parallel to the shear direction $\rangle$. The reconstructed $\beta$ texture can be rotated so as to align the 110 poles with the ideal orientations of bcc simple shear, ${ }^{[60]}$ which is common practice in analysis of friction stir welds. ${ }^{[4,50,52]}$ This would mask an important feature of the present analysis, namely, the cube $\{100\}\langle 001\rangle$ component, ${ }^{[40]}$ whose presence was verified in the ODF. The cube component is a dominant feature of recrystallization textures in rolled cubic materials. ${ }^{[40]}$ As mentioned by Rollet and Wright, ${ }^{[40]}$ the origins of such a high symmetry orientation during recrystallization is not quantitatively understood; however, it is known that they become stronger at higher levels of strain. While the exact level of strain and the strain rates achieved during FSP are unknown, they are both undoubtedly large compared to most metal working processes, which could further promote the formation of a cube texture. In addition, since the stir zone is relatively shallow compared to that in most friction stir welds, the deformation imposed by the shoulder of the tool could also contribute to the formation of a different type of texture. Previous studies ${ }^{[45,49,53]}$ showed that the simple shear model for material flow is adequate to describe material affected by the pin, but it remains unclear whether this type of analysis holds for the shoulder as well. In addition to the cube recrystallization texture component, an orientation close to the $\mathrm{F}$ $\{110\}\langle 001\rangle$ component of the bcc simple shear texture was also identified in the ODF, although its intensity was approximately half that of the cube. In addition, other locations within the stir zone were analyzed and tend to exhibit both deformation and recrystallization textures. $^{[12]}$ The end result, however, is generally the same. The prior $\beta$ grains have equiaxed morphology, are 
approximately $25 \mu \mathrm{m}$ in diameter, and are separated by high-angle grain boundaries. Thus, whether a deformation or recrystallization texture is present is of little practical importance, though it remains an interesting open question.

\section{FURTHER DISCUSSION}

The preceding results have shown that FSP can refine the scale of the microstructure of investment-cast Ti-6-4 and significantly alter the constituent morphology. The $\alpha$-phase grain refinement mechanism was based on a continuous process where low-angle boundaries were developed in the transition zone through recovery processes and evolved into high-angle boundaries as their host $\alpha$ lamellae were swept into the shear zone ahead of the advancing tool. This was accompanied by severe kinking, bending, or compressing of the $\alpha$ lamellae depending on the crystallographic orientation and the orientation of the $\alpha / \beta$ interface with respect to the local interface between the unaffected lamellar structure and the adjacent stir zone. The long axes of the lamellae were reoriented during deformation to align with the local shear direction. In other instances, the $\alpha$ lamellae became thinner as the laths were compressed beneath the tool. The field of structural geology provided insight into these morphological and crystallographic changes that accompanied FSP, albeit at very different length scales. For example, Twiss and Moores $^{[61]}$ showed how lamellar structures respond differently to simple and pure shears. During simple shear deformation, the long axes of acicular features tend to align themselves with the shear direction. This change in morphology is also accompanied by a corresponding lattice rotation, although the relative morphological angle change and lattice rotation do not have to coincide. In contrast, there is no lattice rotation in pure shear, but there is a morphological change resulting in narrowing of one dimension and extension in the other direction of the lamellae. These two types of deformation are shown schematically in Figure 21 and can account for many of the features observed in the transition zone.

The strain necessary to complete the spherodization process, i.e., the strain imposed in the transition zone before the material is swept into the shear zone, can be approximated by examining the results of controlled hot torsion tests performed on fully lamellar Ti-6-4. Poths et al. ${ }^{[27]}$ described the evolution of a fully lamellar microstructure in terms of local continuum strain during hot torsion at $815^{\circ} \mathrm{C}$ at a strain rate of $10^{-3} \mathrm{~s}^{-1}$. In general, kinking of lamellae was first observed at strains around 0.4 in certain colonies, presumably those in crystallographically soft orientations, but there was no significant change in microstructure. At strains between 1.0 and 1.35 , there both kinking and spherodization of the $\alpha$ lamellae was observed. The clusters of spherodized grains were approximately the same size as the colonies in the starting material structure. When a strain of 1.63 was reached, the microstructure was almost completely spherodized, although some colonies persisted to larger

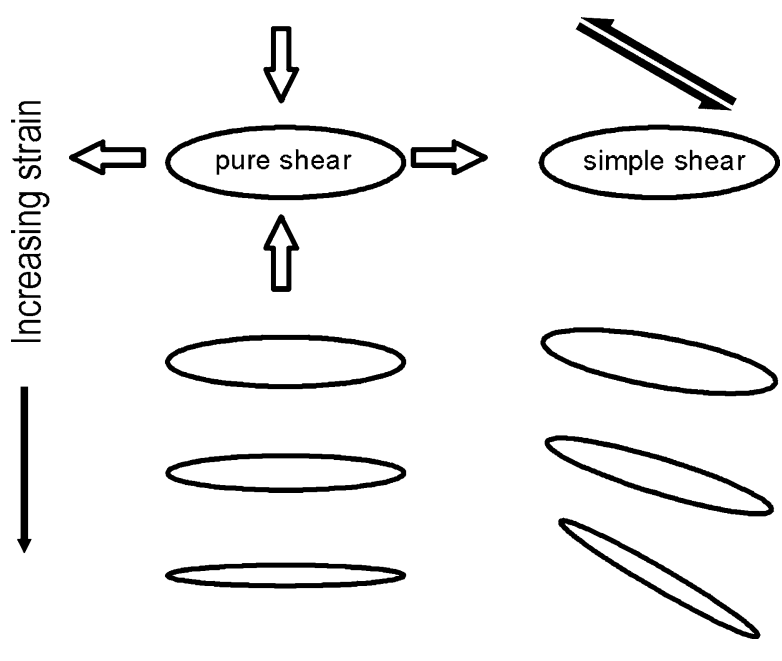

Fig. 21-Shape change of a lath subjected to pure shear and simple shear (schematically). In the latter, the long axis of the lath tends to align with the shear direction.

strains of approximately 3 . Increasing the strain rate to $0.0018 \mathrm{~s}^{-1}$ had no effect on the evolution of microstructure with increasing strain; however, because this increase was less than a factor of 2 , it is not clear how general this apparent rate insensitivity is and if it holds for higher strain rates. In this context, however, it is noteworthy that the strains to initiate and complete globularization for uniaxial compression were similar for strain rates in the range $10^{-3} \mathrm{~s}^{-1}$ to $10 \mathrm{~s}^{-1}$ over the temperature range $1088 \mathrm{~K}$ to $1228 \mathrm{~K} \quad\left(815^{\circ} \mathrm{C}\right.$ to $\left.955^{\circ} \mathrm{C}\right) .{ }^{[25]}$ Thus, it is likely that this rate insensitivity would hold for other strain paths as well. This is an important correlation because it provides a basis for quantifying the level of strain in the transition zone, which appears to be on the order of 2 to 3 , although strains as high as 4 may be required to completely spherodize colonies in crystallographically hard orientations. The strains during the rest of the process are more elusive and modeling efforts are limited by the uncertainty of what is physically happening at the interface between the tool and the material being actively deformed, e.g., if the tool is rigidly coupled to the workpiece or if there is some sliding. Experimental observations on aluminum ${ }^{[58]}$ and titanium ${ }^{[62]}$ alloys suggest that there is a stochastic swapping between interfacial sticking and slipping during FSW. ${ }^{\text {[5] }}$

While the total strain in the stir zone is unknown, the lack of microtexture and the development of a nearly random distribution of grain orientations is a practically important result that can be understood on the basis of crystal plasticity theory. ${ }^{[40,46,49,53]}$ As noted by Rollet and Wright, ${ }^{[40]}$ simple shear textures are rarely strong because there are no stable end positions in orientation space. This is a consequence of the rigid body rotation that is inherent in simple shear, which leads to the development of a steady-state flow of orientations through orientation space. The presence of weak textures is due to the fact that there are points in orientation space where the rigid body rotation is small and grains rotate more slowly with respect to the sample 
reference frame than those in other orientations. This can be contrasted with plane-strain compression (rolling) and axisymmetric deformation processes (extrusion), which have distinct end points in orientation space, ${ }^{[40,63]}$ resulting in well-defined and reproducible textures and the formation of microtextured regions. The preceding discussion was based on simple shear during torsion, which maintains a constant shear direction and shear plane normal. The deformation during FSP is even more complex, because the spatial orientation of the shear plane normal and shear direction are constantly evolving as material flows around the tool, resulting in the elimination of microtextured regions.

\section{CONCLUSIONS}

1. FSP substantially refined the coarse, fully lamellar microstructure near the surface of investment-cast and HIP'ed Ti-6-4 plates. Depending on the peak temperature experienced by the material in the stir zone relative to the $\beta$ transus, the microstructure consisted of either (a) $\sim 1-\mu$ m equiaxed $\alpha$ grains; (b) a smaller volume fraction of similarly sized $\alpha$ grains separated by fine, acicular $\alpha+\beta$; or (c) $\sim 25 \mu \mathrm{m}$ prior $\beta$ grains decorated by a thick grain boundary $\alpha$ layer with fine $\alpha+\beta$ colonies inside.

2. Maintaining constant tool geometry, the peak temperature in the stir zone was a stronger function of tool rotation rate than travel speed. Increasing the former resulted in an increase in the peak temperature in the stir zone and a corresponding decrease in the volume fraction of primary $\alpha$ present during FSP.

3. Spherodization of the $\alpha$ phase in the fully lamellar microstructure was a dynamic process characterized by the formation of low-angle boundaries deep in the transition zone followed by gradual increase in the misorientation of the boundaries with decreasing distance from the stir zone. The relative ease of spherodization was dependent on both the crystallographic orientation of the $\alpha$ phase and the spatial position of the $\alpha / \beta$ interface relative to the local shear plane and shear direction. The equiaxed grains were formed in the transition zone before entering the stir zone. No further coarsening of the equiaxed $\alpha$ grains was observed while they were swept around the friction stir tool and deposited in its wake, even during high $\alpha / \beta$ FSP, where there were few $\alpha / \alpha$ boundaries present at the processing temperature.

4. Despite the large strains imposed during FSP, there was no microtexture present in the stir zone. The $\alpha$-phase texture in the stir zone was essentially random at all locations investigated in the $\alpha / \beta$, high $\alpha / \beta$, and $\beta$ friction stir processed conditions. The presence of weak simple shear texture components and the foundations of crystal plasticity theory provided a basis for understanding this phenomenon.

5. The texture of the $\beta$ phase during supertransus FSP temperature was calculated based on the knowledge of the crystallographic relationships between $\alpha$ variants inherited from the same parent $\beta$ grains. Automated reconstruction of the parent grain orientations revealed that the texture of the $\beta$ phase in the central stir zone exhibited a moderate intensity cube component, consistent with a recrystallization texture, although deformation texture components have also been identified in other regions of the stir zone.

\section{ACKNOWLEDGMENTS}

This work was funded by the Office of Naval Research under Grant No. N00014-09-1-0259. We are grateful to program managers Drs. J. Christodoulou and J. Deloach for their support and encouragement. The investment-cast material used in this study was provided by J. Ault, Precision Castparts Corp. We thank Professor A.P. Reynolds and Dr. W. Tang, University of South Carolina, for processing several cast titanium plates and for many discussions related to FSP. Additional processing by Dr. Z.T. Li and J. Fisher, Edison Welding Institute, is also appreciated. Several of the functions used in the automated $\alpha \rightarrow \beta$ reconstruction were part of the $\operatorname{OdfPf}$ package distributed by P.R. Dawson and D. Boyce et al., Deformation Processes Laboratory at Cornell University (anisotropy.mae.cornell.edu). The assistance of Dr. M.C. Brandes (The Ohio State University (OSU), Columbus, $\mathrm{OH}$ ) with the STEM work and the helpful discussions regarding recrystallization reactions with Professor T.R. McNelley (Naval Postgraduate School, Monterey, CA) are greatly appreciated. Finally, A. Young (OSU) is acknowledged for his help in preparing this manuscript.

\section{REFERENCES}

1. Z.Y. Ma, A.L. Pilchak, M.C. Juhas, and J.C. Williams: Scripta Mater., 2008, vol. 58, pp. 361-66.

2. J.E. Spowart, Z.Y. Ma, and R.S. Mishra: in Friction Stir Welding and Processing II, K.V. Jata, M.W. Mahoney, R.S. Mishra, S.L. Semiatin, and T.J. Lienert, eds., TMS, Warrendale, PA, 2003, pp. 243-52.

3. Z.Y. Ma, S.R. Sharma, R.S. Mishra, and M.W. Mahoney: Mater. Sci. Forum, 2003, vols. 426-432, pp. 2891-96.

4. M.W. Mahoney, W.H. Bingel, and R.S. Mishra: Mater. Sci. Forum, 2002, vols. 426-432, pp. 2843-48.

5. K. Oh-Ishi and T.R. McNelley: Metall. Mater. Trans. A, 2004, vol. 35 A, pp. 2951-61.

6. K. Oh-Ishi and T.R. McNelley: Metall. Mater. Trans. A, 2005, vol. 36A, pp. 1575-85.

7. A.L. Pilchak, M.C. Juhas, and J.C. Williams: Metall. Mater. Trans. A, 2007, vol. 38A, pp. 401-08.

8. A.L. Pilchak, Z.T. Li, J.J. Fisher, A.P. Reynolds, M.C. Juhas, and J.C. Williams: in Friction Stir Welding and Processing IV, R.S. Mishra, M.W. Mahoney, T.J. Lienert, and K.V. Jata, eds., TMS, Warrendale, PA, 2007, pp. 419-27.

9. A.L. Pilchak, M.C. Juhas, and J.C. Williams: Proc. 11th World Ti 2007 Conf., M. Ninomi, S. Akiyama, M. Ikeda, M. Hagiwara, and K. Maruyama, eds., Kyoto, Japan, 2007, pp. 1723-26.

10. A.L. Pilchak, M.C. Juhas, and J.C. Williams: Weld. World, Res. Suppl., 2008, vol. 52 (9-10), pp. 60-68. 
11. A.J. Ramirez and M.C. Juhas: THERMEC'2003, Materials Science Forum, 2003, vols. 426-432, pp. 2999-3004.

12. A.L. Pilchak: Ph.D. Dissertation, The Ohio State University, Columbus, OH, 2009.

13. Y. Zhang, Y.S. Sato, H. Kokawa, S.H.C. Park, and S. Hirano: Mater. Sci. Eng. A, 2008, vol. 485, pp. 448-55.

14. S. Mironov, Y. Zhang, Y.S. Sato, and H. Kokawa: Scripta Mater., 2008, vol. 59, pp. 27-30.

15. T.R. McNelley: Naval Postgraduate School, Monterey, CA, private communication, 2009

16. G. Lütjering and J.C. Williams: Titanium, Springer-Verlag, New York, NY, 2003.

17. L. Zhou, H.J. Liu, P. Liu, and Q.W. Liu: Scripta Mater., 2009, vol. 61 (6), pp. 596-99.

18. N. Stefansson, S.L. Semiatin, and D. Eylon: Metall. Mater. Trans. A, 2002, vol. 33A, pp. 3527-34.

19. M. Rubal: Master's Thesis, The Ohio State University, Columbus, OH, 2009.

20. M.C. Juhas, G.B. Viswanathan, and H.L. Fraser: Proc. 2nd Symp. on Friction Stir Welding, Gothenburg, Sweden, 2000.

21. R.D. Doherty, D.A. Hughes, F.J. Humphreys, J.J. Jonas, D. Juul Jensen, M.E. Kassner, W.E. King, T.R. McNelley, H.J. McQueen, and A.D. Rollett: Mater. Sci. Eng. A, 1997, vol. 238, pp. 219-74.

22. F.J. Humphreys: Acta Mater., 1997, vol. 45 (10), pp. 4231-40.

23. M. Peters, G. Lütjering, and G. Ziegler: Z. Metallkd., 1983, vol. 74 , pp. $274-82$.

24. T.R. Bieler and S.L. Semiatin: Int. J. Plast., 2002, vol. 18, pp. 1165-89.

25. S.L. Semiatin, V. Seetharaman, and I. Weiss: Mater. Sci. Eng. A, 1999, vol. 263, pp. 257-71.

26. N. Stefansson and S.L. Semiatin: Metall. Mater. Trans. A, 2003, vol. 34A, pp. 691-98.

27. R.M. Poths, G. Angella, B.P. Wynne, W.M. Rainforth, S.L. Semiatin, and J.H. Beynon: Metall. Mater. Trans. A, 2004, vol. 35A, pp. 2993-3001.

28. S.L. Semiatin, N. Stefansson, and R.D. Doherty: Metall. Mater. Trans. A, 2005, vol. 36A, pp. 1372-76.

29. R.W. Cahn: J. Inst. Met., 1949, vol. 76, p. 121.

30. J.C. Williams, R.G. Baggerly, and N.E. Paton: Metall. Mater. Trans. A, 2002, vol. 33A, pp. 837-50.

31. J.C. Williams, A.W. Sommer, and P.P. Tung: Metall. Trans., 1972, vol. 3, pp. 2979-84.

32. L. Germain, N. Gey, M. Humbert, P. Bocher, and M. Jahazi: Acta Mater., 2005, vol. 53, pp. 3535-43.

33. L. Germain, N. Gey, M. Humbert, P. Vo, M. Jahazi, and P. Bocher: Acta Mater., 2008, vol. 56, pp. 4298-4308.

34. I. Weiss, F.H. Froes, D. Eylon, and G.E. Welsch: Metall. Mater. Trans. A, 1986, vol. 17A, pp. 1935-47.

35. J.C. Chesnutt, C.G. Rhodes, and J.C. Williams: FractographyMicroscopic Cracking Processes, ASTM STP 600, ASTM, Philadelphia, PA, 1976, pp. 99-138.

36. W.G. Burgers: Physica, 1934, vol. 1, pp. 561-86.

37. M.G. Glavicic, P.A. Kobryn, T.R. Bieler, and S.L. Semiatin: Mater. Sci. Eng. A, 2003, vol. 346, pp. 50-59.

38. M.G. Glavicic, P.A. Kobryn, T.R. Bieler, and S.L. Semiatin: Mater. Sci. Eng. A, 2003, vol. 351, pp. 258-64.
39. C. Cayron: Acta Cryst. Sect. A Foundations Crystallogr., 2006, vol. A62, pp. 21-40

40. U.F. Kocks, C.N. Tomé, and H.-R. Wenk: Texture and Anisotropy: Preferred Orientations in Polycrystals and Their Effect on Materials Properties, Cambridge University Press, New York, NY, 1998.

41. N.E. Paton, J.C. Williams, and G.P. Rauscher: in Titanium: Science and Technology, Proc. 2nd Int. Conf. on Titanium, R.I. Jaffee and H.M. Burte, eds., Plenum Press, New York, NY, 1973, vol. 2, pp. 1049-69.

42. T.J. Lienert, K.V. Jata, R. Wheeler, and V. Seetharaman: Proc. Joining of Advanced and Specialty Materials III, ASM INTERNATIONAL, Materials Park, OH, 2001, pp. 160-66.

43. N. Gey and M. Humbert: Acta Mater., 2002, vol. 50, pp. 27787.

44. N. Karogal: Master's Thesis, The Ohio State University, Columbus, $\mathrm{OH}, 2002$

45. M.M.Z. Ahmed, B.P. Wynne, W.M. Rainforth, and P.L. Threadgill: Scripta Mater., 2008, vol. 59, pp. 507-10.

46. B. Beausir, L.S. Tóth, and K.W. Neale: Acta Mater., 2007, vol. 55, pp. 2695-2705.

47. R.W. Fonda, J.A. Wert, A.P. Reynolds, and W. Tang: Sci. Technol. Weld. Join., 2007, vol. 12 (4), pp. 304-10.

48. W. Cai, J. Mabon, and P. Bellon: Wear, 2009, vol. 267 (1-4), pp. $485-94$.

49. J.-H. Cho and P.R. Dawson: Metall. Mater. Trans. A, 2006, vol. 37A, pp. 1147-64.

50. K.E. Knipling and R.W. Fonda: Scripta Mater., 2009, vol. 60, pp. $1097-1100$

51. D.P. Field, T.W. Nelson, Y. Hovanski, and K.V. Jata: Metall. Mater. Trans. A, 2001, vol. 32A, pp. 2869-77.

52. A.P. Reynolds, E. Hood, and W. Tang: Scripta Mater., 2005, vol. 52, pp. 491-94.

53. J.-H. Cho, D.E. Boyce, and P.R. Dawson: Mater. Sci. Eng. A, 2005, vol. 398, pp. 146-63.

54. A.A. Salem and S.L. Semiatin: Mater. Sci. Eng. A, 2009, vol. 508, pp. 114-20.

55. D. Bhattacharyya, G.B. Viswanathan, R. Denkenberger, D. Furrer, and H.L. Fraser: Acta Mater., 2003, vol. 51, pp. 4679-91.

56. R.W. Fonda, J.F. Bingert, and K.J. Colligan: Proc. 5th Int. Symp. on Friction Stir Welding, Metz, France, Sept. 14-16, 2004.

57. J. Baczynski and J.J. Jonas: Metall. Mater. Trans. A, 1998, vol. 29 A, pp. 447-62.

58. J. Schneider, R. Beshears, and A.C. Nunes Jr.: Mater. Sci. Eng. A, 2006, vols. 435-436, pp. 294-304.

59. H.-J. Bunge: Texture Analysis in Materials Science: Mathematical Methods, Butterworth \& Co., Berlin, 1982, pp. 55-118.

60. J. Baczynski and J.J. Jonas: Acta Mater., 1996, vol. 44 (11), pp. $4273-88$.

61. R.J. Twiss and E.M. Moores: Structural Geology, W.H. Freeman \& Co, New York, NY, 1992.

62. A.L. Pilchak, W. Tang, H. Sahiner, A.P. Reynolds, and J.C. Williams: Metall. Mater. Trans. A. DOI:10.1007/s11661-010$0439-4$.

63. H.P. Lee, C. Esling, and H.-J. Bunge: Text. Microstr., 1988, vol. 7, pp. $317-37$. 